\title{
THE PUBLIC REALM SUPPORTING SOCIAL INTERACTIONS AND PRIORITIES OF IMPROVEMENT
}

\author{
Khaled Y. Mohamed, Ayman M. Zakaria Eraqi , Michael M. Ibrahim \\ Architecture Dept., Faculty of fine arts, University of Minia, Minia, Egypt \\ *Corresponding author Email: Ayman.ibrahim@mu.edu.eg
}

\begin{abstract}
: -
The development of cities depends on several urban and architectural potentials. Among those potentials are public spaces. Public spaces activate the cultural, social, and economic features of a city; as well as enhancing healthy life. The rise of rapid urbanization, and increased migration from rural to urban areas, led to the emergence of various urban problems such as bad planning and narrow urban environments. Consequently, public spaces diminished in cities, and several unused urban spaces popped out. This has stimulated planners to assimilate this problem by introducing the Public Realm concept. The public realm is defined as publicly owned zones (such as streets, plazas, squares, and intermediate places), in which various social interactions are practiced. Besides, the public realm was found to have common features that enhance its role in city development. As many cities sought to improve the public realm; such as London, Dublin, Leeds, etc.; improvements in social, economic, and environmental conditions in the city started to come up. Hence, this paper addresses public realm definitions and concepts, as well as the common features of the public realm supporting social interactions, to understand the priorities and methodology of improving the public realm in cities..
\end{abstract}

Keywords: Public Realm- Public Spaces - Intermediate places - Healthy life. 


\title{
Vol. 42, No. 1, January2023
}

\author{
المجال العام الأاعم للتفاعلات الاجتماعية وأولويات التحسين \\ خالا يوسف محمد 1 أيمن محمد زكريا 2 \\ 2,1 مدرس بقسم العمارة - كلية الفنون الجميلة - جامعة المنيا \\ 3احث بقسم العمارة - كلية الفنون الجميلة - جامعة المنيا \\ Ayman.ibrahim@mu.edu.eg
}

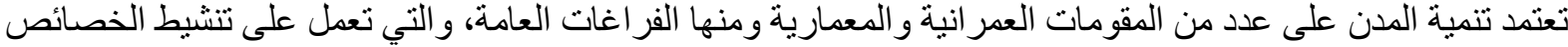

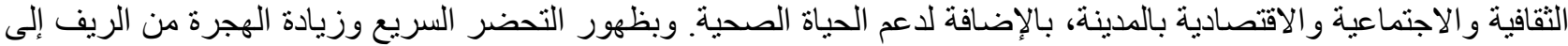

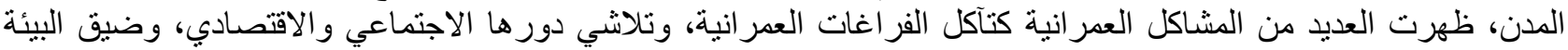

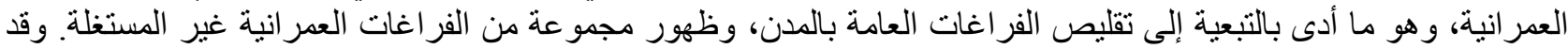

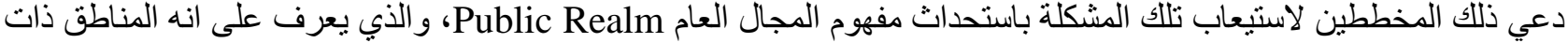

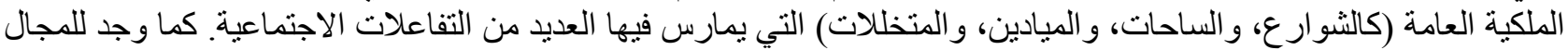

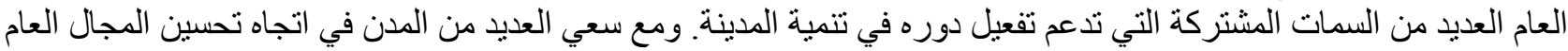

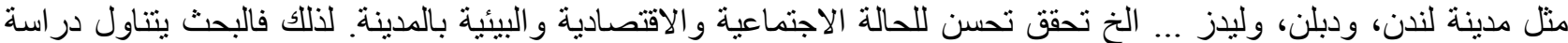
تعاريف ومفاهيم المجال العام وبحث السمات المشتركة للمجال العام الداعم للتفاعلات الاجتماعية، للوصول لفهم اولويات ومنهجية تحسين المجال العام بالمدن.

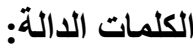

المجال العام - التفاعلات الاجتماعية - الفراغات العامة - المتخلات - الحباة الصحية

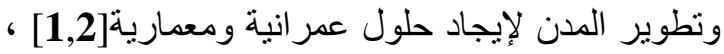
فظهر مفهوم المجال العام، والذي عرف بشكل عالِ عام على انه النه الاماكن ذات الملكية العامة و المتاحة لجميع سكان المئ المدينة

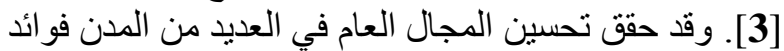

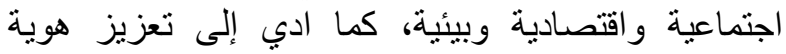

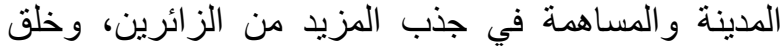
فراغات آمنة، ونوفير حياة صحية، وتحسين جودة حياة المينة

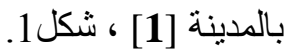

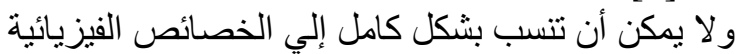

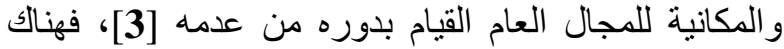

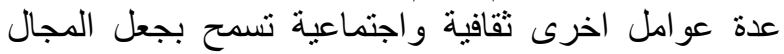

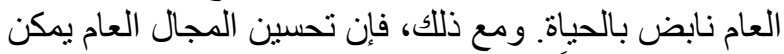

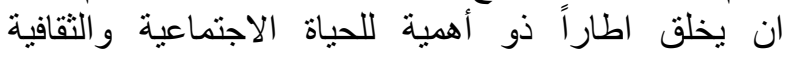

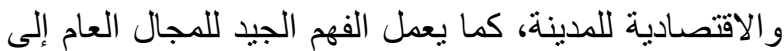

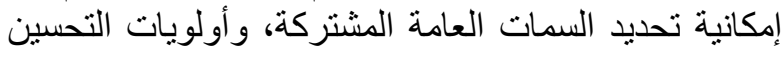

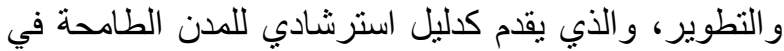

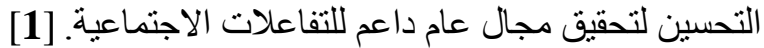

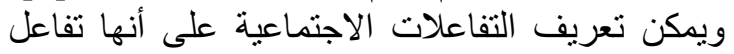

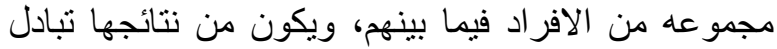

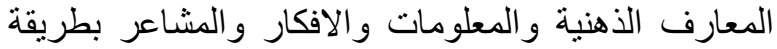

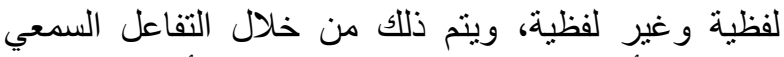

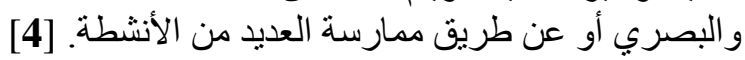

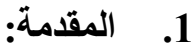

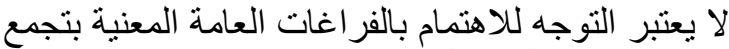

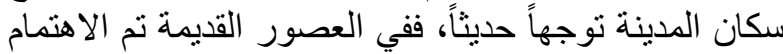

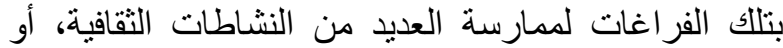

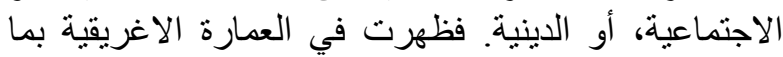

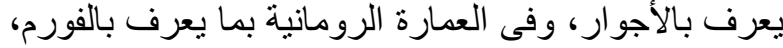

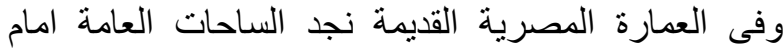

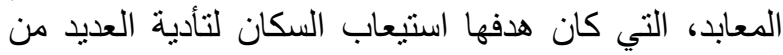

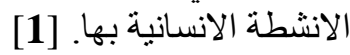
ومع تطور العصر ظهرت النهانية التهنة الصناعية، وتبعها

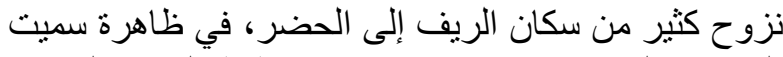

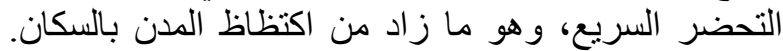

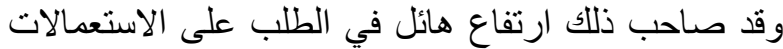

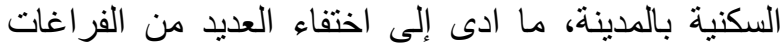
العامة تحت وطأة الكثافات السكانية المرتفعة بالمدن القائمة الماته،

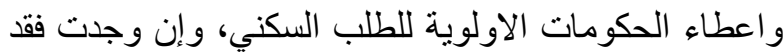
عانت من الاهمال وتدهور العناصر المعمارية بها.

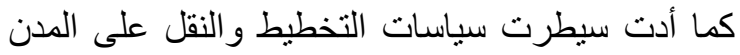

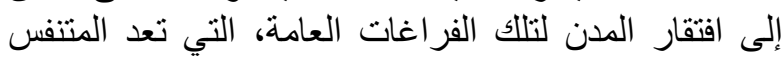

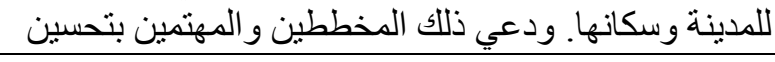
Received:8 March, 2021, Accepted:10 May, 2021 
Vol. 42, No. 1. January 2023

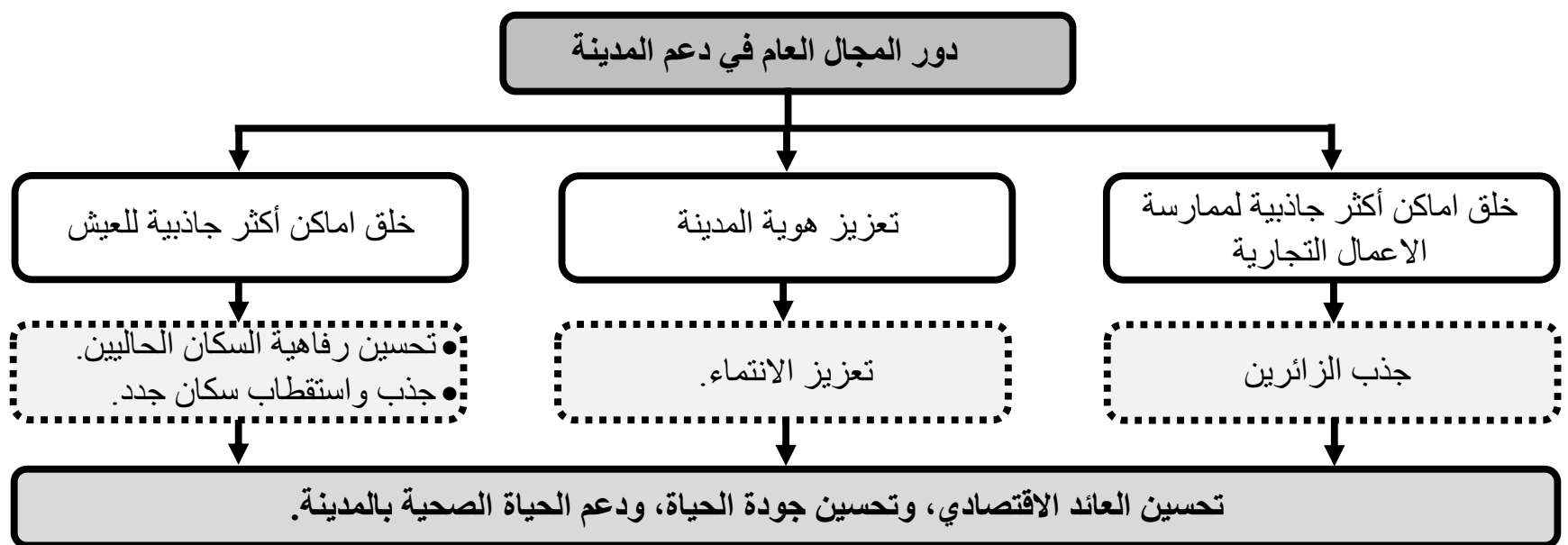

\section{شكل1: دعم المجال العام لتحسين جو انب الحياة المختلفة بالمدينة [5] بتصرف.}

مختلف الانشطة الثقافية والاجتماعية والاقتصادية، وتعمل على تأسيس هوية المجتمع وتعزيز الطابية الطابع المحلى و الشعور

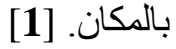

بينما يري Steven peterson أن المجال العام كيانات

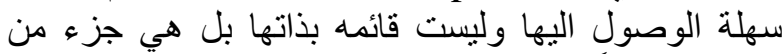

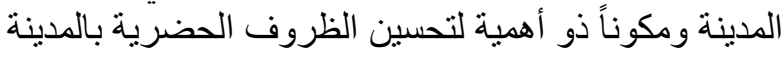

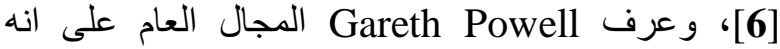
الفضاء المحيط بنقاط الوصول للمدينة، والذي يؤثر على على الثي

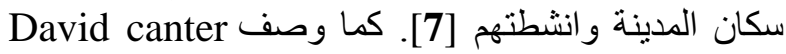
المجال العام على انه المكان النموذجي الذئى يتطلب نوفير

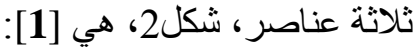

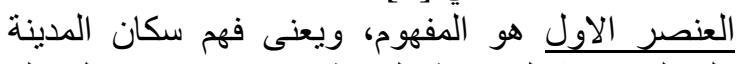

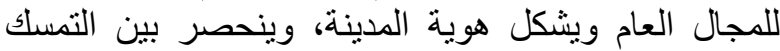

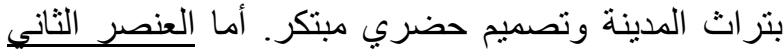

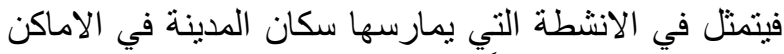

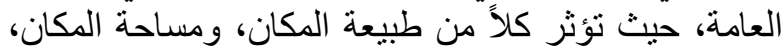

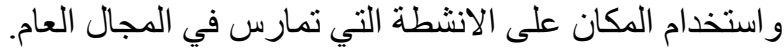

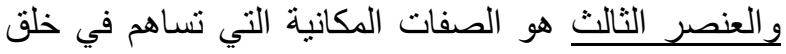

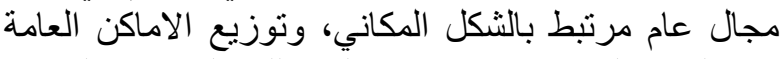

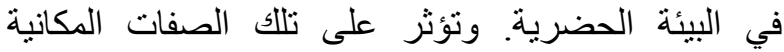

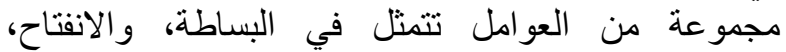

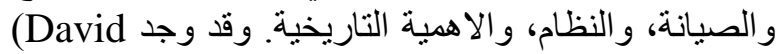
canter) فقد أي عنصر إلى حدوث خلل في توصيف المجال العام.
وتكمن مشكلة البحث في سيطرة مظاهر التحضر

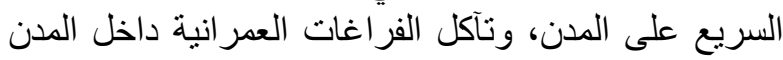

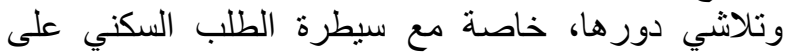
المدن، وهو ما انعكس في خصائي خصائص المدينة الاجنماعية الماية و الاقتصادية وجاذبيتها للز ائرين.

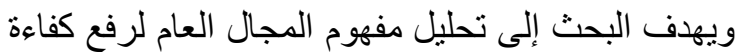

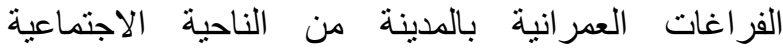

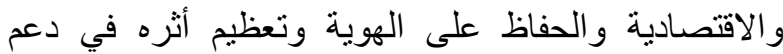

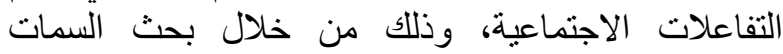

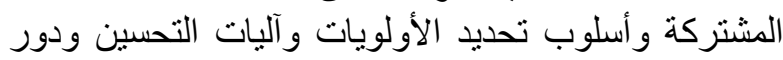
الجهات الفاعلة بالمدينة.

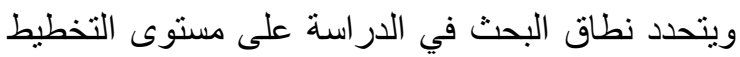

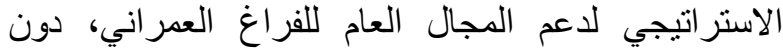

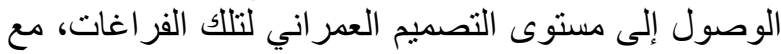

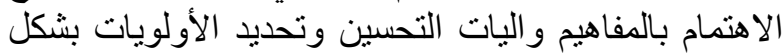
عام دون التطرق لامكانيات التطبيق على الوضع الونع المحلي في تللك الورقة البحثية لضيق المساحة.

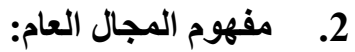

يعتبر المجال العام من أحد الركائز الاساسية لتنمية المدن

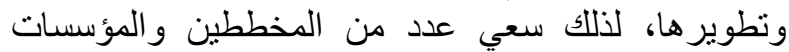

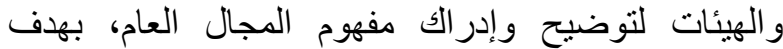
توضيح ومعرفة مفرداته وسماته المشتركة. فيرى Anirban Adhya, Peter Eisenman and Aspa Gospondi أن المجال العام يضم جميع الفراغات العمر انية ذات الملكية

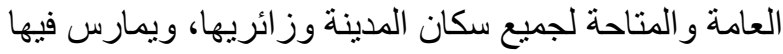


Vol. 42, No. 1, January2023

الاحساس بالتنوع و الانتماء و الاهمية التاريخية في المناطق

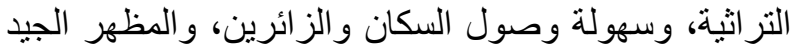

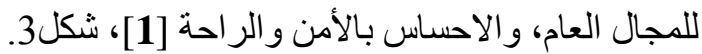

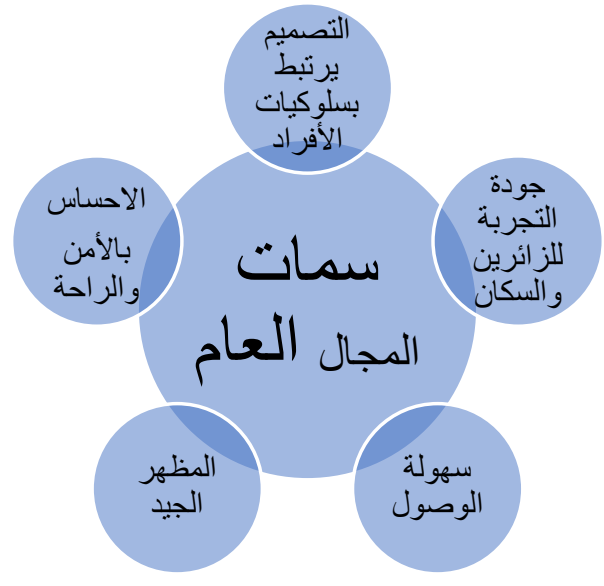

شكل 3: سمات المجال العام الداعم لتنمية المدينة

4. اختيار المدن محل الدراسة وتحليل المدن:

بعد استعر اض مفهوم وتعريف المجال العام وسماته،

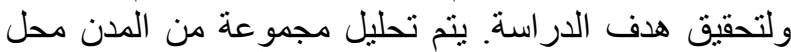
الدر اسة، والتي تم اختيار ها وتحليلها بناءاً على مجموعة من من التحن

المعايير. أ- اختيار المدن محل الاراسة:

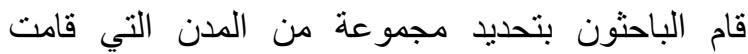
بتحسين المجال العام، ووضع معايير لاختيار الماندة المدن محل

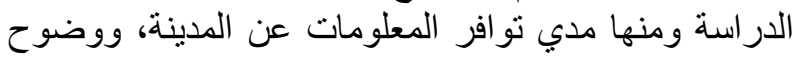

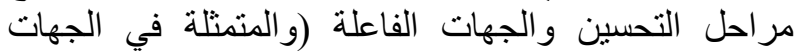

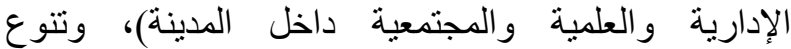

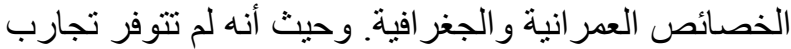

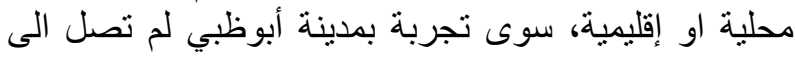

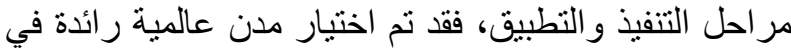
هذا المجال وهي: مدينة لندن بالمملكة المتحدة البريطانية،

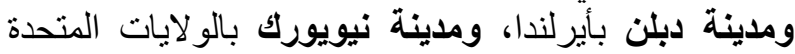

$$
\text { ب- ت تحليل المدن: }
$$

يتم تحليل المدن محل المدن الداسة من خلال التعريف

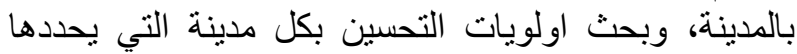

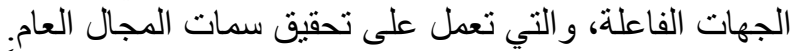
وقد تختلف اولويات تحسين المجال العام بكل مدينة طبقاً

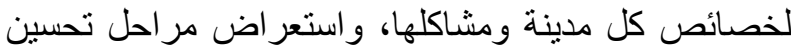
المجال العام، ودر اسة سمات المجال العام، ثم عرض وضن للجهات الفاعلة.

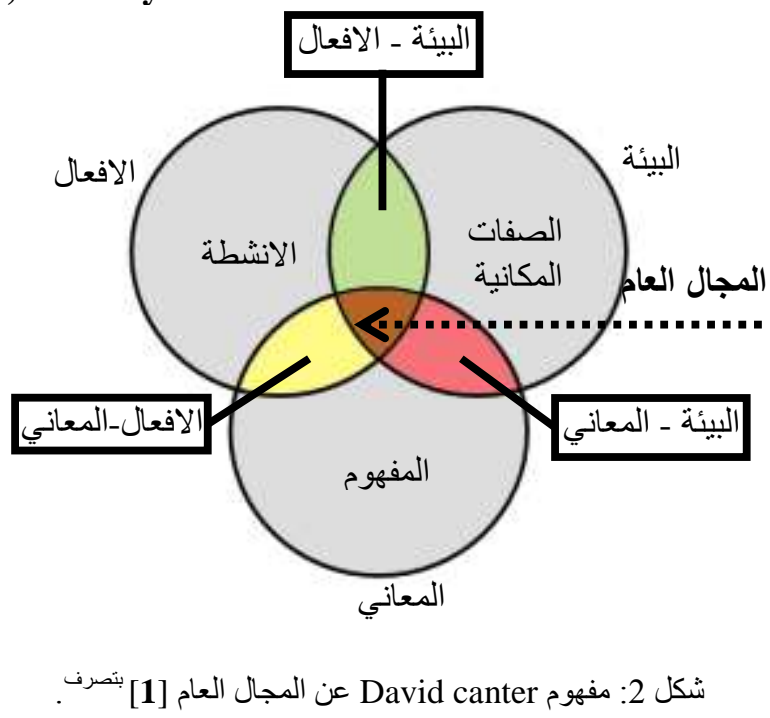

Ontario Professional Planners قمام بتعريف المجال العام على انه الاماكن (OPPI) Institute

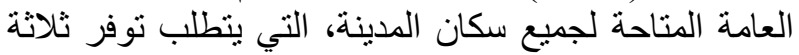

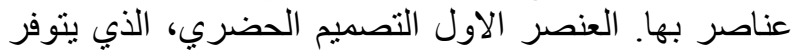
فيه المرونة لاستيعاب كافة الانشطة المختلفة، وسهولة الإنة

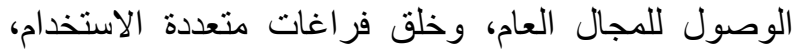

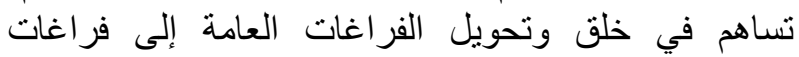

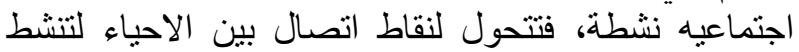

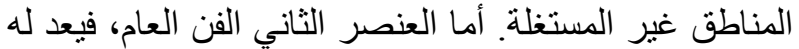

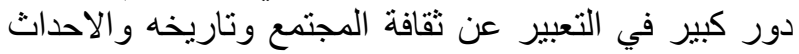

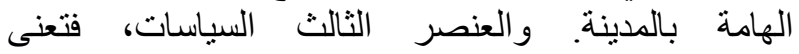
الاستراتيجيات التي تقوم بها المدن لدعم وتطوير المجالئال

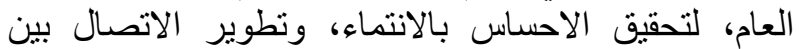

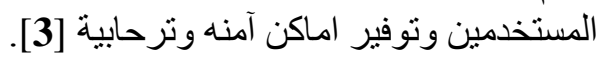

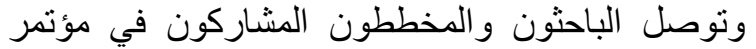

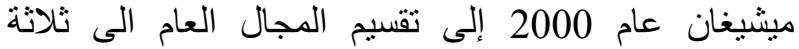

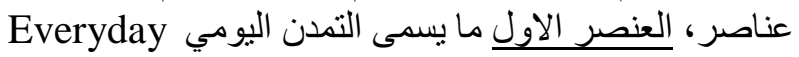

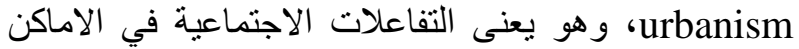
العامة اثثاء ممارسة الانشطة اليومية. اما العنصر الثناني الثاني

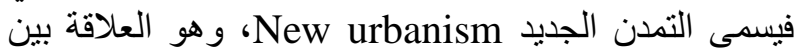
التفاعلات الاجتماعية والثكل المادي للتيد للمكان، بينما العنصر

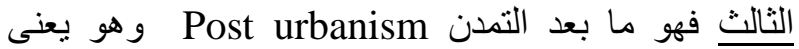

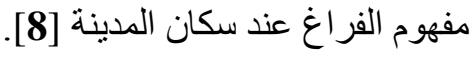
3. سمات المجال العام:

يمتلك المجال العام مجمو عة من السمات وهي خصائص

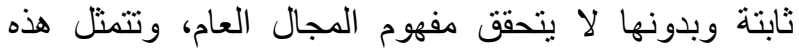
السمات في أن يكون التصميم مرتبط بأنشطة الافر اد و أفعالهم

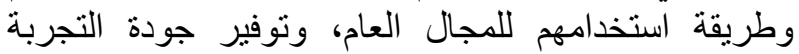
للسكان و الزائرين في الفراغات العامة مما يؤدى إلى إلى لئل 
وبناءاً على ذللك، تم تقسيم تحسين المجال العام الى ثلاثة

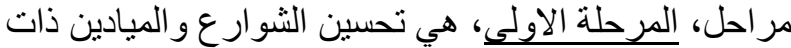

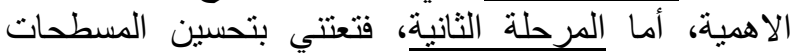

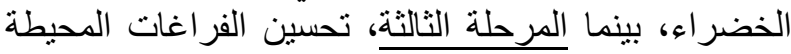

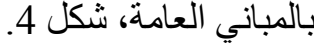

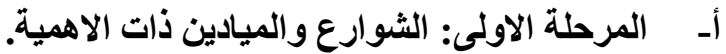

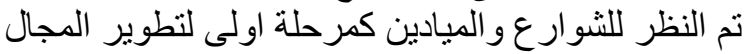

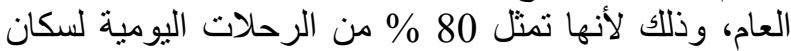

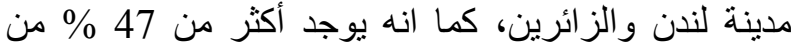
الاعمال التجارية خارج وسط مدينة لندن. و عليه قامت هيئة

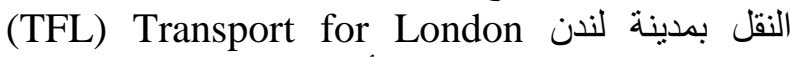
بتحديث الطرق بقيمة تصل إلى أربع مليار ات جنية إسترليني

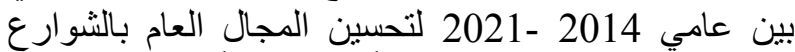
و الميادين، وتقديم اماكن أكثر امناً واخضر اراً وجاذي التبية.

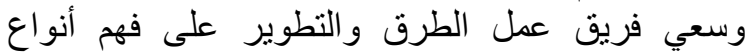

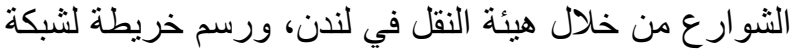

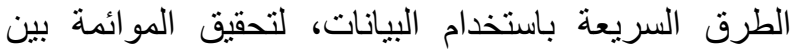

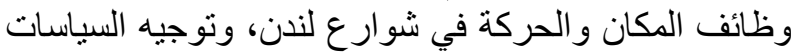

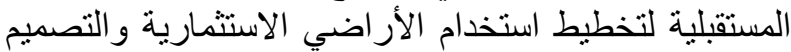

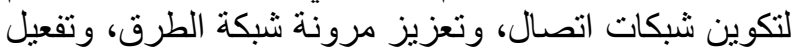
النقل النشط Active transport

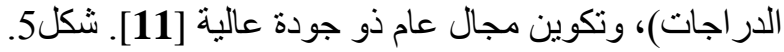

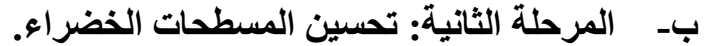

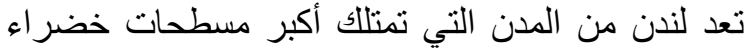

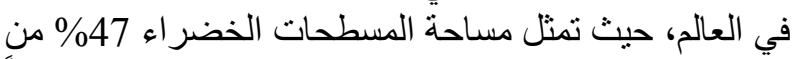
مساحة المدينة، لذا تمثل البنية التحتية الخضراء المبناء عنصراً اساسياً في المدينة.
1-4 مدينة لندن:

The River Thames تقع مدينة لندن علي نهر التيمز لتئنة جنوب المملكة البريطانية المتحدة، وتبلغ لنانغ مساحتها 1583

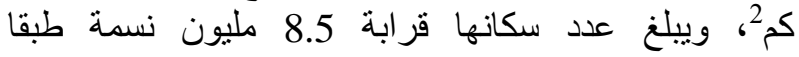
لإحصائية 2016، وتعتبر اكثر المدئية المدن جاذبية للسكان

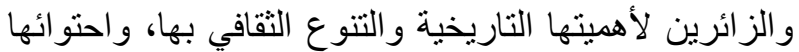

علي العديد من الخدمات الترفيهية [9].

1-1-4 مراحل تحسين المجال العام بمدينة لندن:

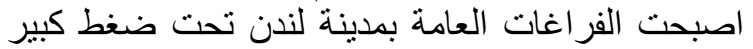

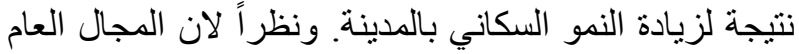

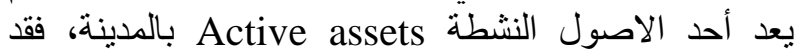

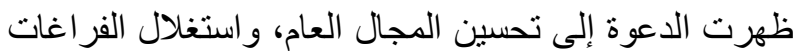

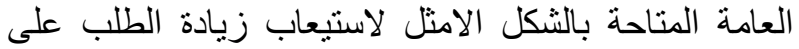

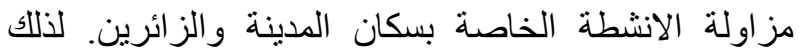

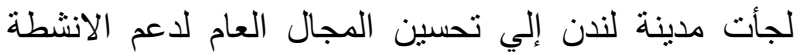

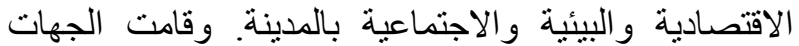
المسئولة عن تطوير المجال العام بتحديد اولويات الإية المدينة

$$
\text { [10] ؛ }
$$

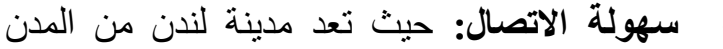
كبيره الحجم، لذلك ظهرت الأهرت الحاجة إلى تسهيل

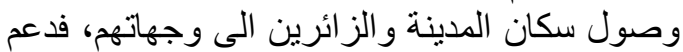

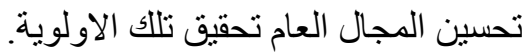
مدى اقبال السكان والزائرين على الفراغ الفات العات العامة:

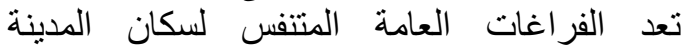

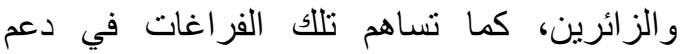

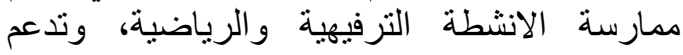
الحفاظ على هوية المدينة.

\section{أولويات تحسين المجال العام لمدينة}

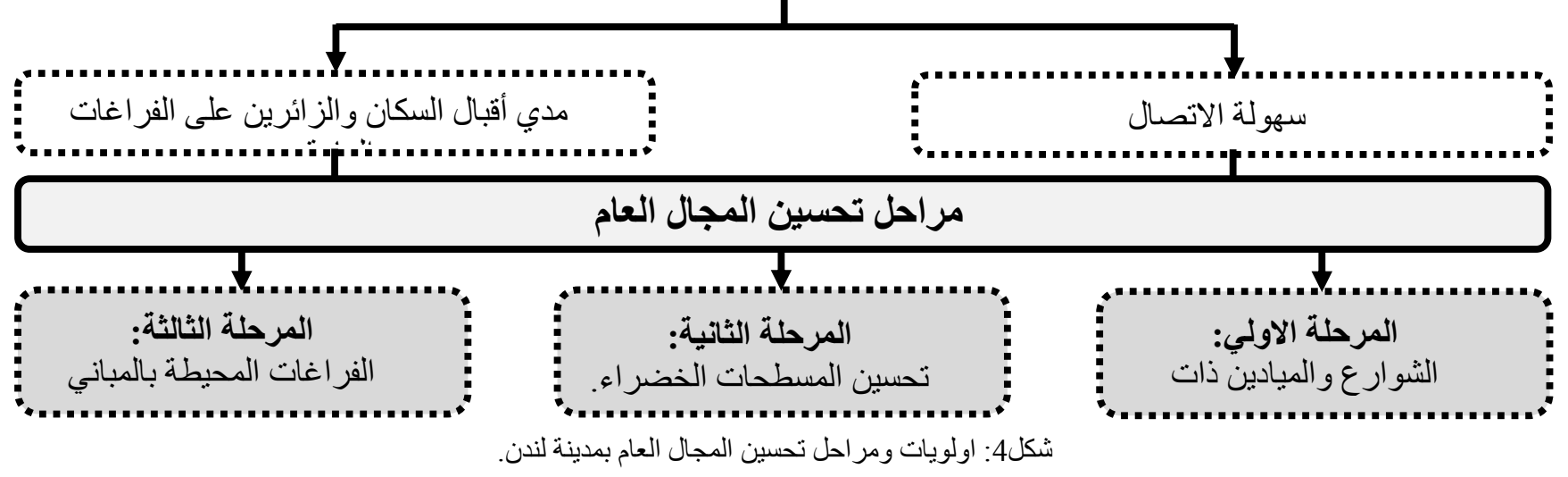


Vol. 42, No. 1, January2023

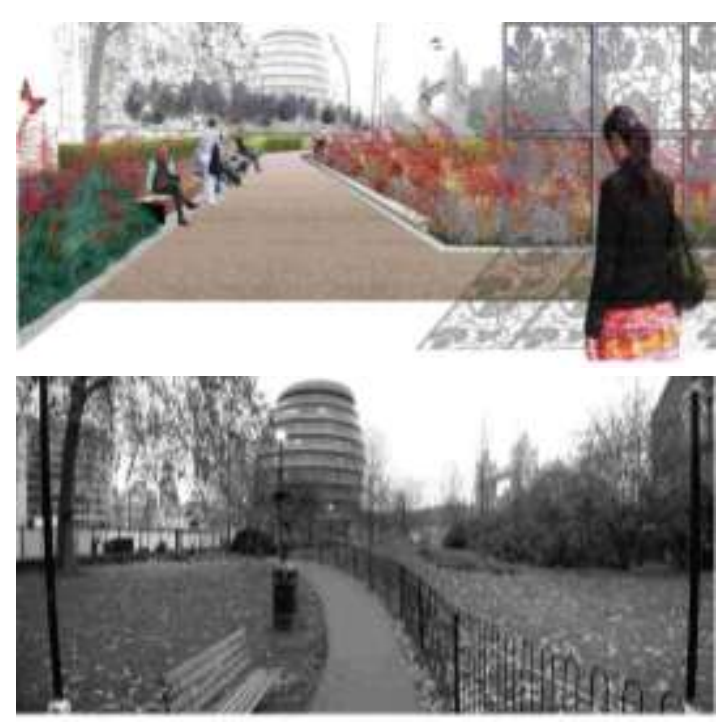

شكل 6: تحسين المسطحات الخضراء بمدينة لندن قبل

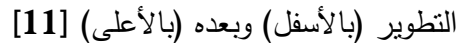

مجلس المدينة، والجهات المجتمعية، و والجهات العلمية. وعملت الجهات على تحقيق التكامل للوصول إلى هدف التى لته التحسين.

\section{أ- جلس المدينة:}

قام المجلس بإعداد رؤية شاملة لتنمية المدينة ومنها تحسين المجال العام، والتي يقودها القطاع العام بشكل دئل

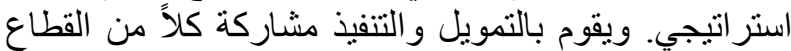
العام والخاص، نتيجة انخفاض ميز انيات القطاع التهاع العام. وقد

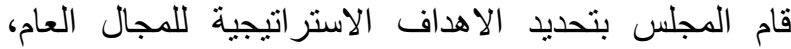

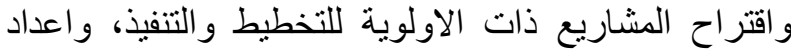

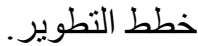

\section{ب- الجهات العلمية:}

قامت الجهات العلمية بعمل العديد من الدراسات منها

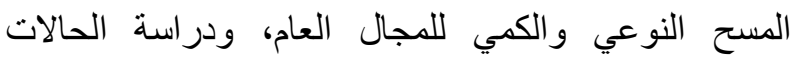

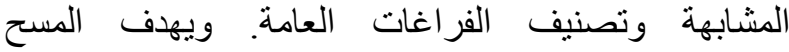
النوعيQQualitative، للوصول إلى امكانيات و ومعوقات إنهات

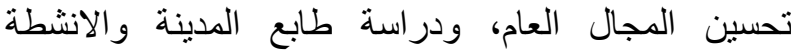

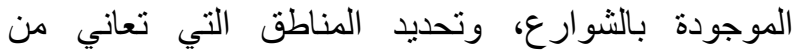
الازدحام المروري وحالات البيئة الفقيرة، وكذلك المناطق لئق

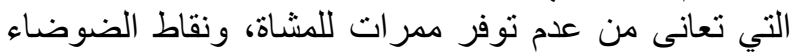

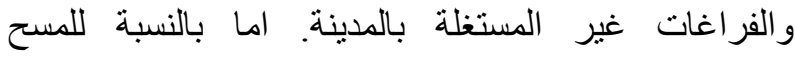
الكميQuantitative، فهو يقوم بتحديد الصفات المكانية للفر اغات العامة، وتقييم المطلوب تخصيصده من الفراغات و المسطحات اللازمة للاستخدامات المختلفة ومدى كثافتها،
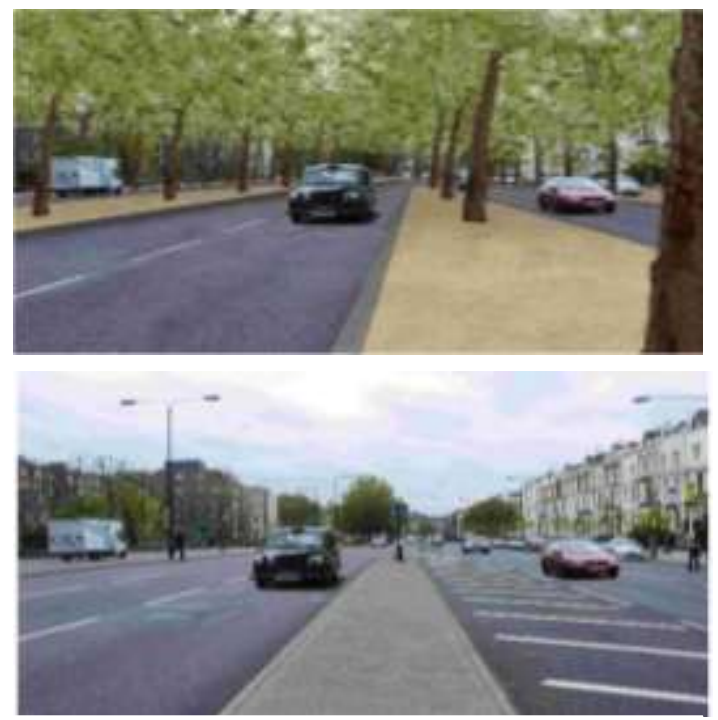

شكل 5: تحسين المجال العام لثوارع مدينة لندن قبل

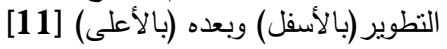

لذلك فقد قام مسئولي تحسين المجال العام بجعل المرحلة

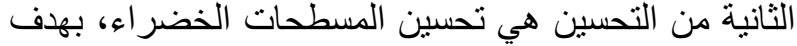

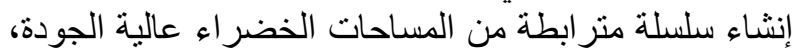

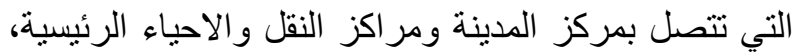
وتساهم في دعم السفر المستدام، وتحقيق انماط الحياة الصحية الصية الصية إلى جانب دعم النمو الاقتصادي، كما يعمل تحسين إنين

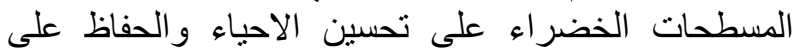
هوية المدينة [11,10]. شكل المكي 6.

ج- المرحلة الثالثة: الفراغات المحيطة بالمباني العامة.

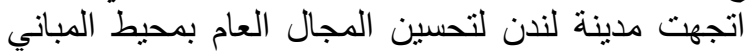

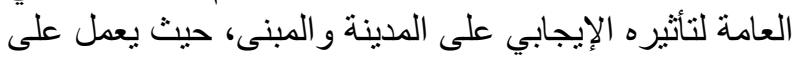

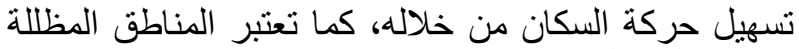

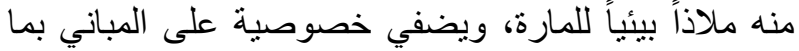

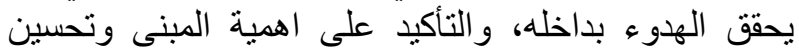
القدرة على استيعاب المستخدمين، وتحسين الربط بلين بين الفراغ الفين الداخلي و الخارجي [11,12]. شكل 7. 2-1-4 سمات المجال العام بمدينة لندن:

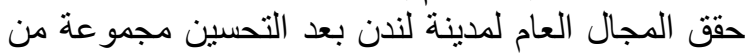

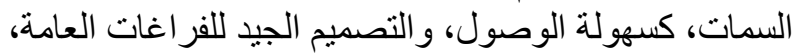

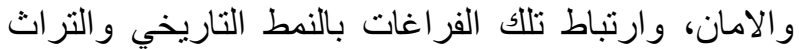

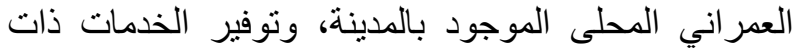
الجودة [9]. - العبراني 3-1-4 الجهات الفاعلة: تضافرت جهود الجهات الفاعلة Stakeholders في الفي المدينة لتحسين المجال العام، وتمثلت تلك الجهات الفاعلة في في 
Vol. 42, No. 1. January 2023

مقاطعات، وتعد من أكثر المدن اكتظاظاً بالسكان بأيرلندا، وكذلك تعتبر أكثر المدن جذبا للسكان نظر أ لأهميتها التاريخية و الثقافية و التجارية [13:

1-2-4 مراحل تحسين المجال العام بمدينة دبلن:

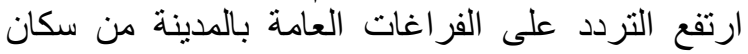

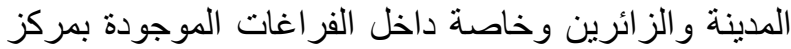

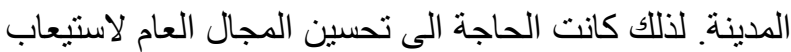

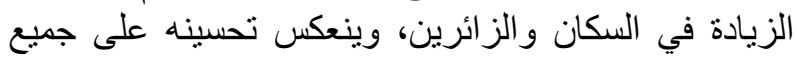

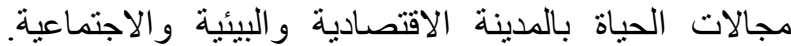

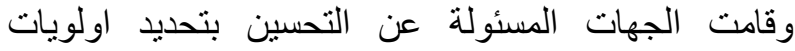
المدينة، والتي تتمثل في الاتي:

سهول الوصول: في خطة مدينة دبلن 2011 20112017، قام مجلس المدينة بإعداد رؤية للمدية دينة دينة

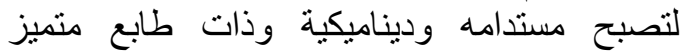

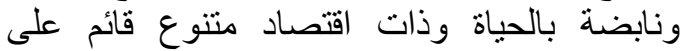

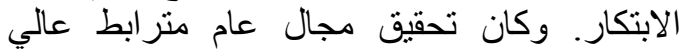
الجودة هو مفتاح لتحقيق هذه الرؤية، وكذللك تحقيق التوازن بين المطالب المكانية للمجال العام وبين العين

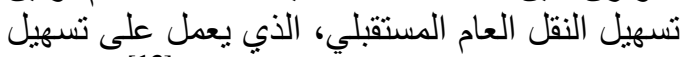

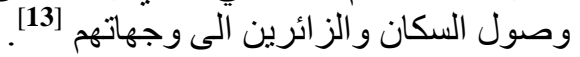
• هوية المدينة: يعتبر المجال العام جزءا اساسياً في

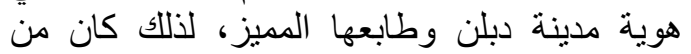

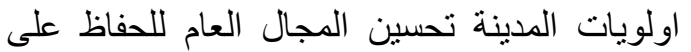

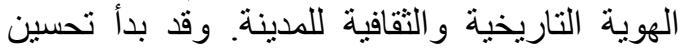

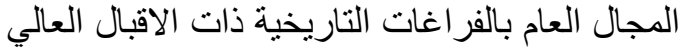

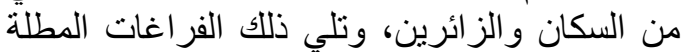

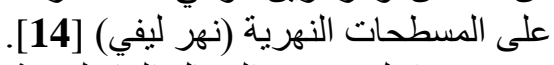

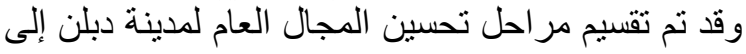

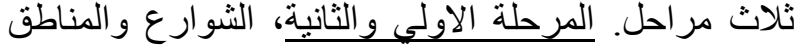

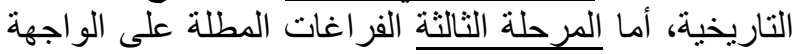

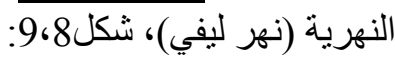

أ- المرحلة الاولى و والثانية الثوارع والمناطق التاريخية: - (المرية

يعد المجال العام المساحة الرئيسية للحركة والتداول

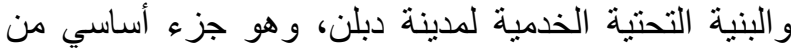

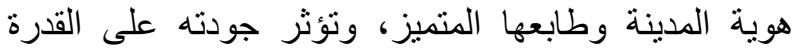

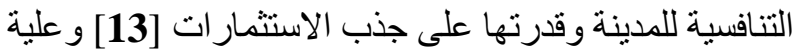
تم النظر الى الثوارع والمناطق الناريخية كمرحلة اولى الثى وثانية، لدعم حركة سكان المدينة والزائرين [14]، التينة التي تبلغ
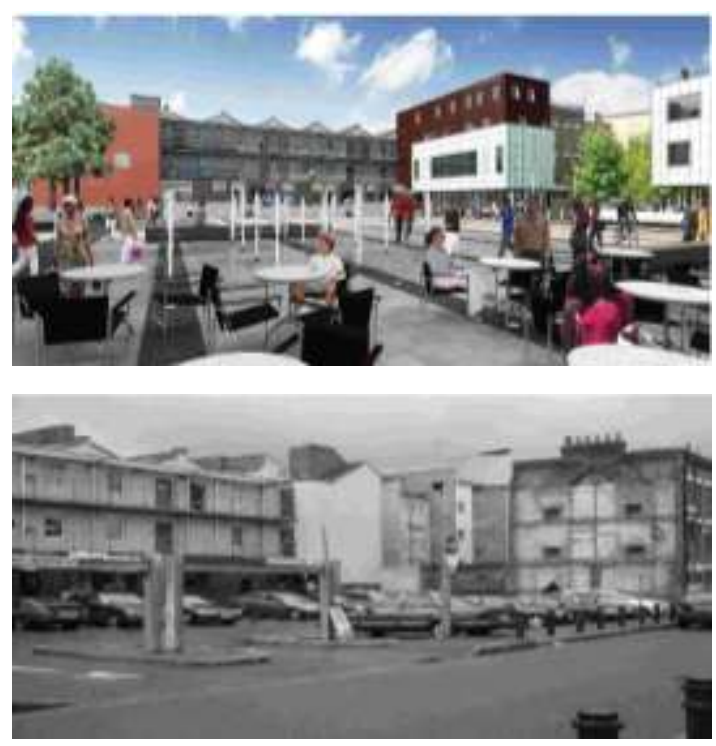

شكل 7: تحسين المجال العام للفراغات العامة قبل

التطوير (بالأسفل) وبعده (بالأعلى) [11:

واعداد المشاة، وتحديد اماكن انتظار وسائل النقل العام

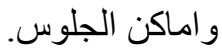

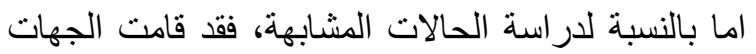

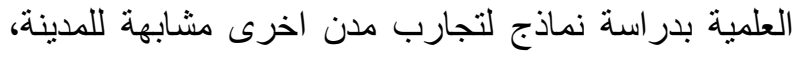

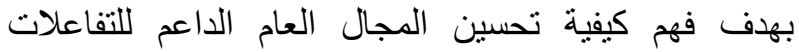

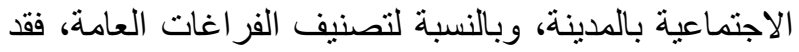

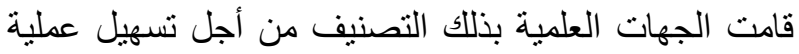
التحسين و المساهمة في تحديد اولوياته بالمدينة، وتم تصنية التيفها

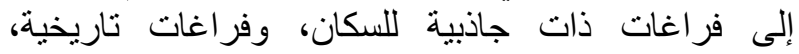

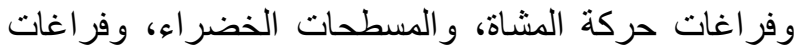

استضافة الاحداث الهامة [10,9].

ج- الجهات المجتمعية: ساهم المجتمع المدني في مدينة لندن في تحسين المنام المجال المنال

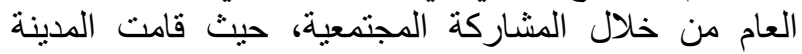
بطرح استبيان مجتمعي لتحديد مشكلات وامكانيات المجال العام قبل إجراء عملية التحسين، اما بعد عملية التحسين فتم اعداد استبيانات لقياس مدى رضية إنا سكان المدينة و الزائرين عن عملية التحسين [9].

2-4 مدينة دبلن: تعتبر مدينة دبلن عاصمة ايرلندا وتأسست عام 1191م،

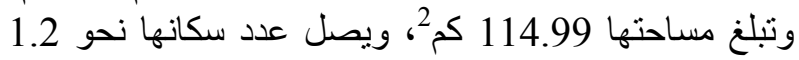
مليون نسمة طبقا لإحصائية 2016. تضم المدينة خمس 
Vol. 42, No. 1, January2023

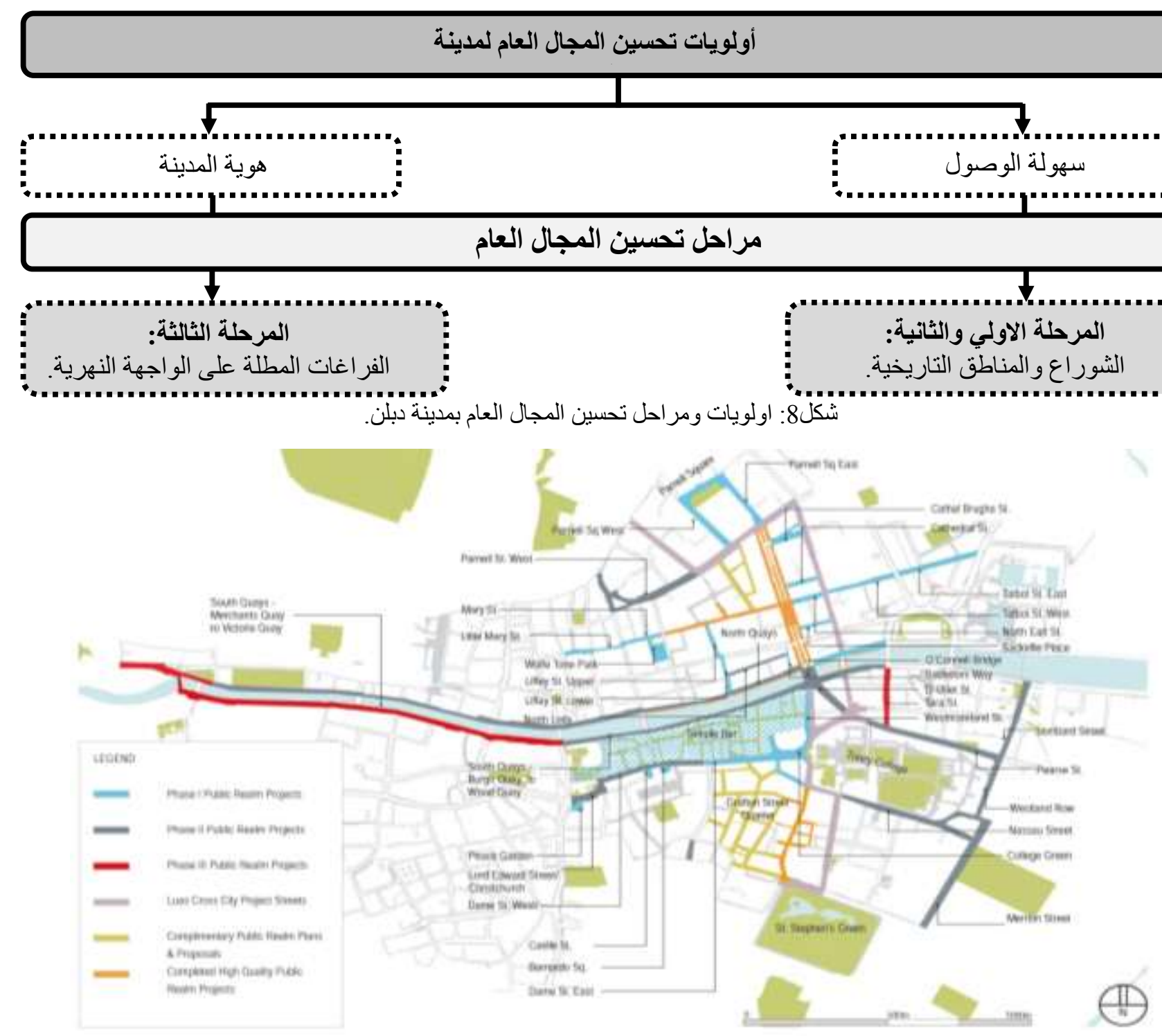

شكل 9: مر احل تحسين المجال العام لمدينة دبلن [14]

• ان تكون تلك المناطق غير منفصلة بطرق مرور

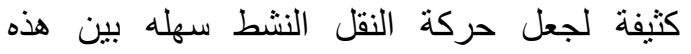

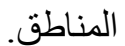
ألا تكون تلك المناطق معرضة لضغط كبير من الازدحام وتمتلك مساحات لخلق مناطق للنقل النشط.

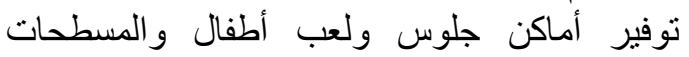
الخضر اء لإعطاء فرصة لـاء للاسترخاء والاستمتاع

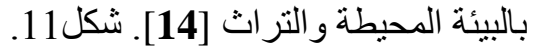

أكثر من نصف مليون شخص في حاجة للانتقال الى وسط

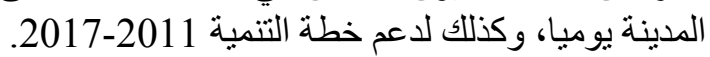

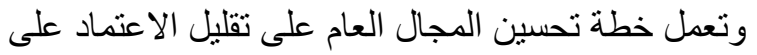

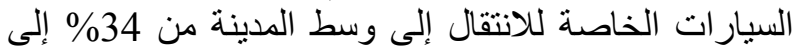

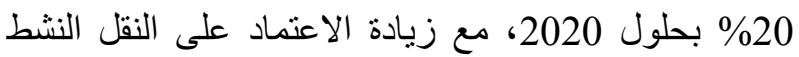
بنسبة 20\% - 25\% من إجمالي الرحلات اليومية [13].

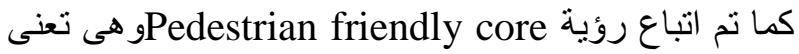
بتحويل الثوارع الثي روني مناطق حيوية، تسمح بوجود تنوع

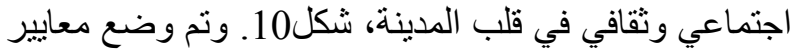
للشو ارع المر اد تحسينها كالاتي: فئل 
Vol. 42, No. 1. January 2023

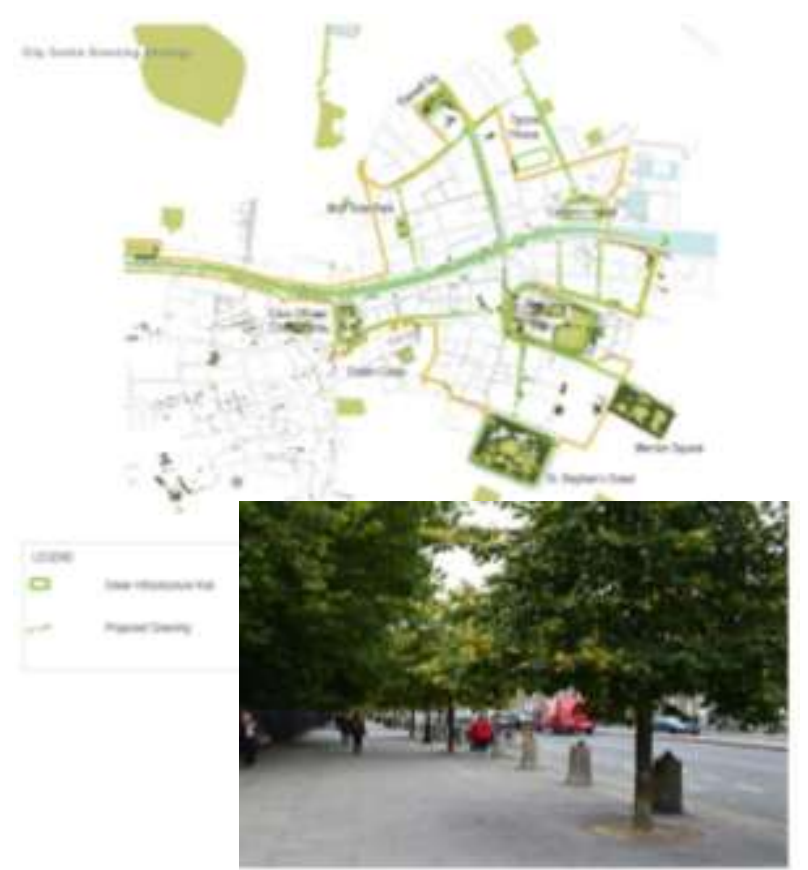

شكل 11 : زيادة المسطحات الخضر اء بمدينة دبلن لتحسين

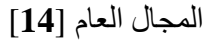

والاحساس بالراحة والترحاب، والاحساس بهوية المدينة التاريخي (الحفاظ على الهوية) [14].

3-2-4 الجهات الفاعلة في عملية تحسين المجال العام لمدينة دبلن:

قامت المدينة بإعداد خطة تطوير شاملة لمدينة دبلن

2017-2011. وتم النظر إلى تحسين المجال العام كأحد

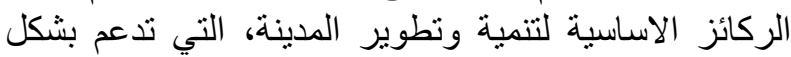

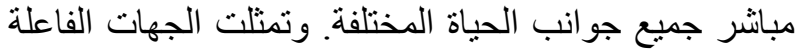
في مجلس المدينة، و الجهات المجتمعية، والجهات العيات العلمية.

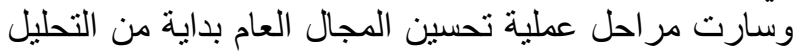

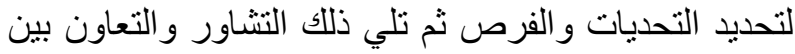
الجهات المختلفة وصولا إلى التو افتى على على مبادئ ومحاور اساسية للتحسين واعداد مخطط استراتيجي لتحسين المجال

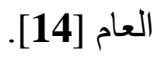

\section{أ- مجلس المدينة:}

قام مجلس المدينة بإعداد رؤية شاملة لتطوير وتحسين

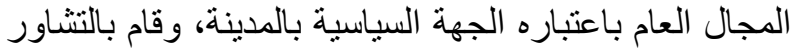

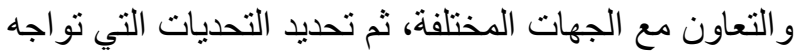
المدينة وكيفية التغلب عليها، كما قام المجلس بتقديم الداعم المالي للمشرو عات التي تم التوصل اليها من خلال الدمام الدراسات.
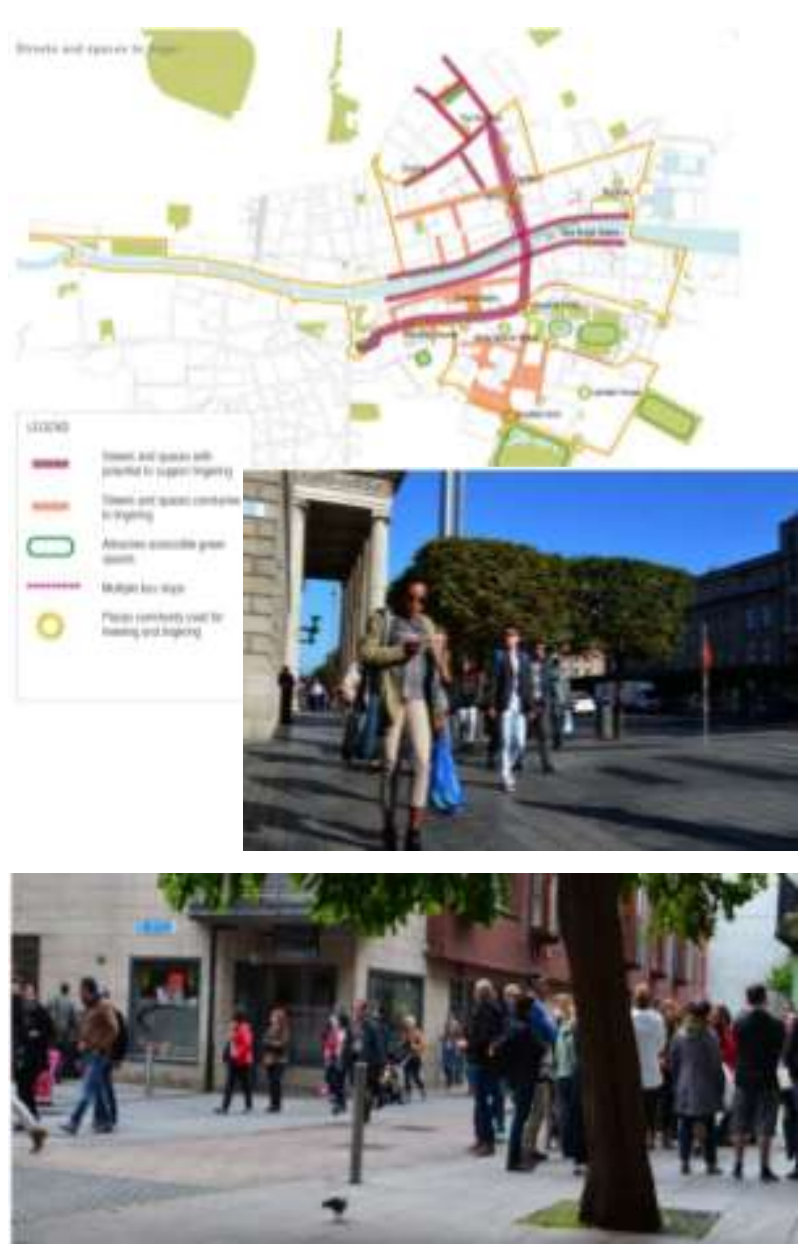

شكل10: :تحويل الثوارع و الساحات لمسار ات حيوية لتسهل

الوصول ودعم الانتقال النشط [14]

ب- المرحلة الثالثة الفراغات المطلة على الواجهة النهرية (نهر ليفي):

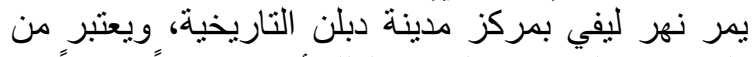

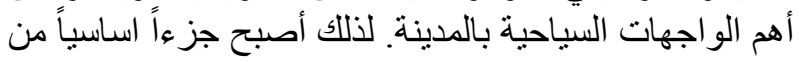

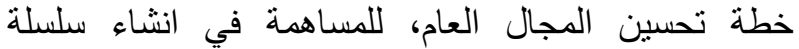
مثر ابطة من المناطق ذات الجودة العالية، التي تدعم بالتبعية

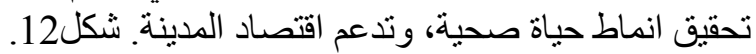
2-2-4 سمات المجال العام لمدينة دبلن:

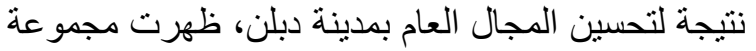

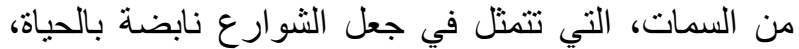
وزيادة المسطحات الخضراء لتباء وبالتالي التنوع في في البيئة المحيطة، وجودة تصميم المجال العام، وتوفير الامن فئل 
الولايات المتحدة، وتعتبر المدينة أهم المراكز التجارية

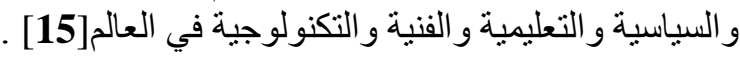

1-3-4 مراحل تحسين المجال العام بمدينة نيويورك:

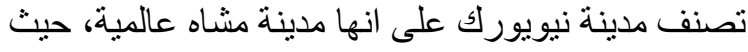

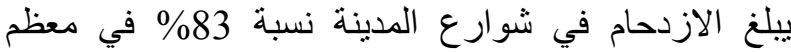

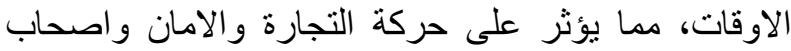

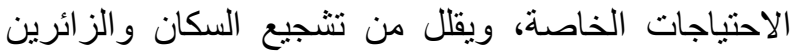

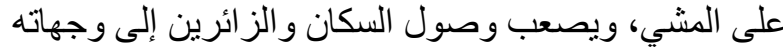
[16]. وبالتالي ظهرت الحاجة إلى تحسين المجال العام، وذلك بتحديد اولويات المدينة التي تتمثل في:

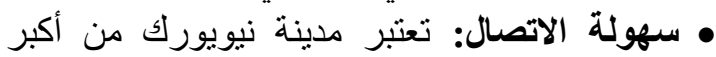

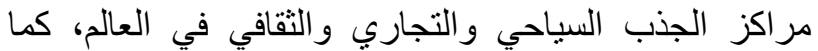

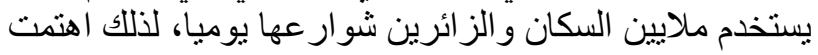

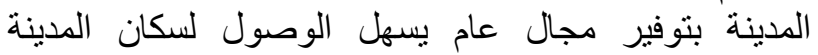
و الزائرين [16].

• تحسين جودة المناطق العامة: يمثل المجال العام

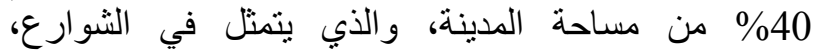

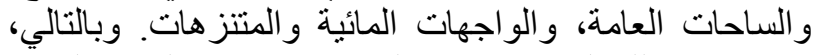

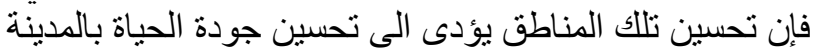
وتحسين الصحة العامة لسكان المدينة والزائرين ويدعم القتصاد

المدينة [15]

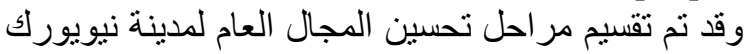

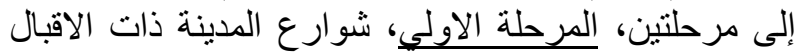

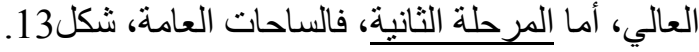
أ- المرحلة الاولى شوارع المدينة ذات الاقبال العالي:

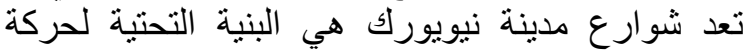

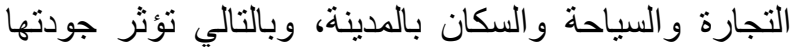
على قدرة المدينة على جذب الاستثمار ات و السياح. و علية تم النظر اليها كمرحلة اولى لعملية التحسين، فتم عمل برنات ولنامج Sustainable streets \& Plan NYC مستوى الامن، شكل14، من خلال تقليل السرعات في الطرق

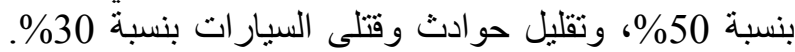

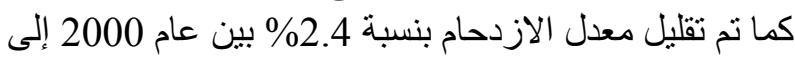

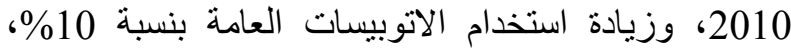
وزيادة استخدام الدراجات بنسبة 13\%ة. وتم تحقيق زيادة الادة

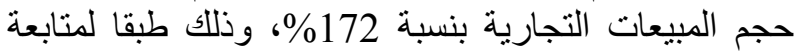

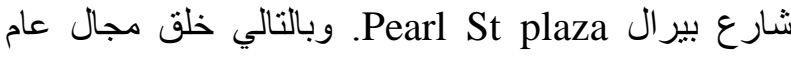
ديناميكي ومزدهر ومرن [17].
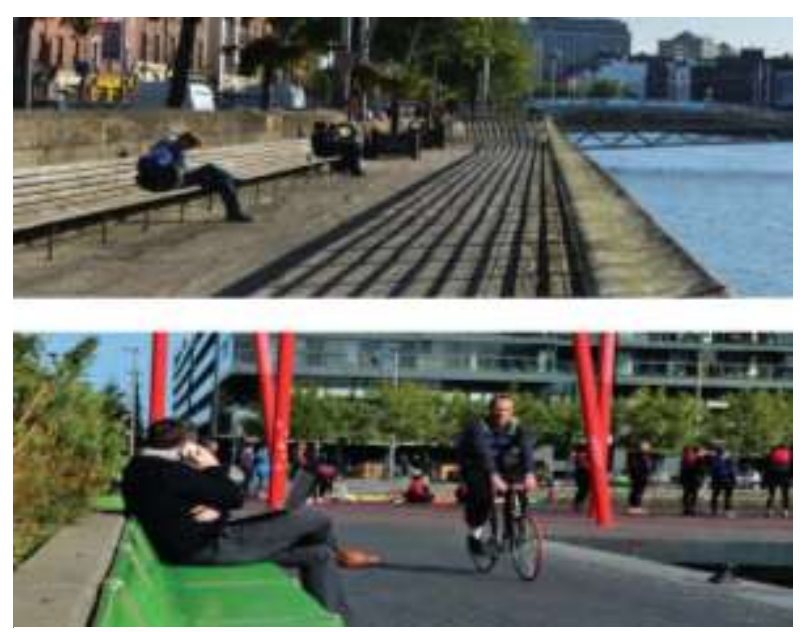

شكل12: تحسين المجال العام للو اجهات النهرية لدينة دبلن [14]

ب- الجهات المجتمعية:

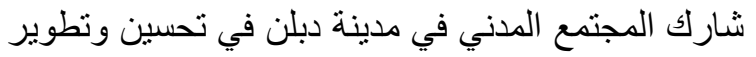

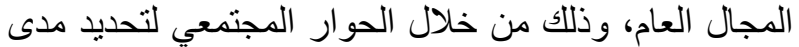

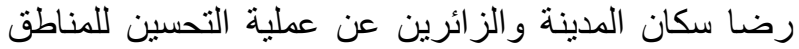

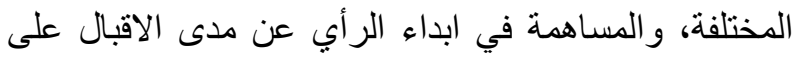

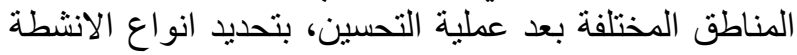
المرغوب في در استها بالمجال العام.

\section{ج- الجهات العلمية:}

قامت الجهات العلمية بعمل دارسات المستح النوعي و الكمي للمجال العام، حيث يهدف المستح النوعي إلى تلى تحديد

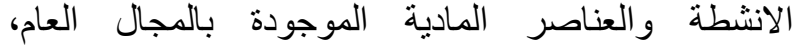

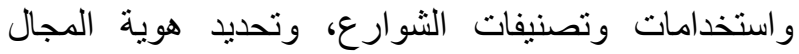

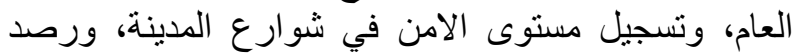

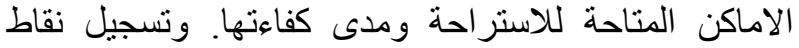

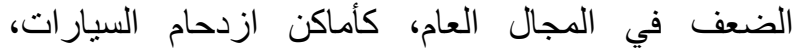

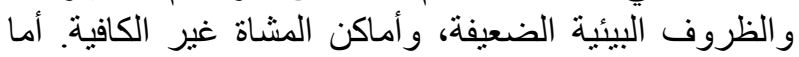

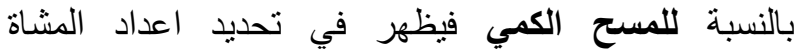
و المساحات المطلوبة لهم، وبالتالي تحديد نقاط الضعف و والقية القوة

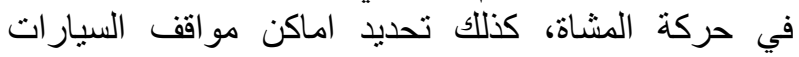
واماكن الجلوس بالثوارع ورصد مسار ات سير الدراجات الديات

3-4

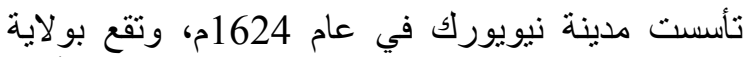
نيويورك بالولايات المتحدة الامريكية. تعد المدينة من أكبر الكائ

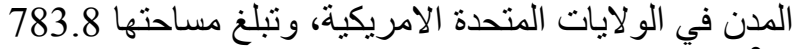

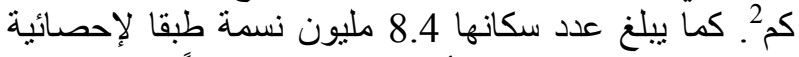
2019. تعد المدينة من أكثر المدن اكتظاظاً بالسكان في لإحنا 
Vol. 42, No. 1. January 2023

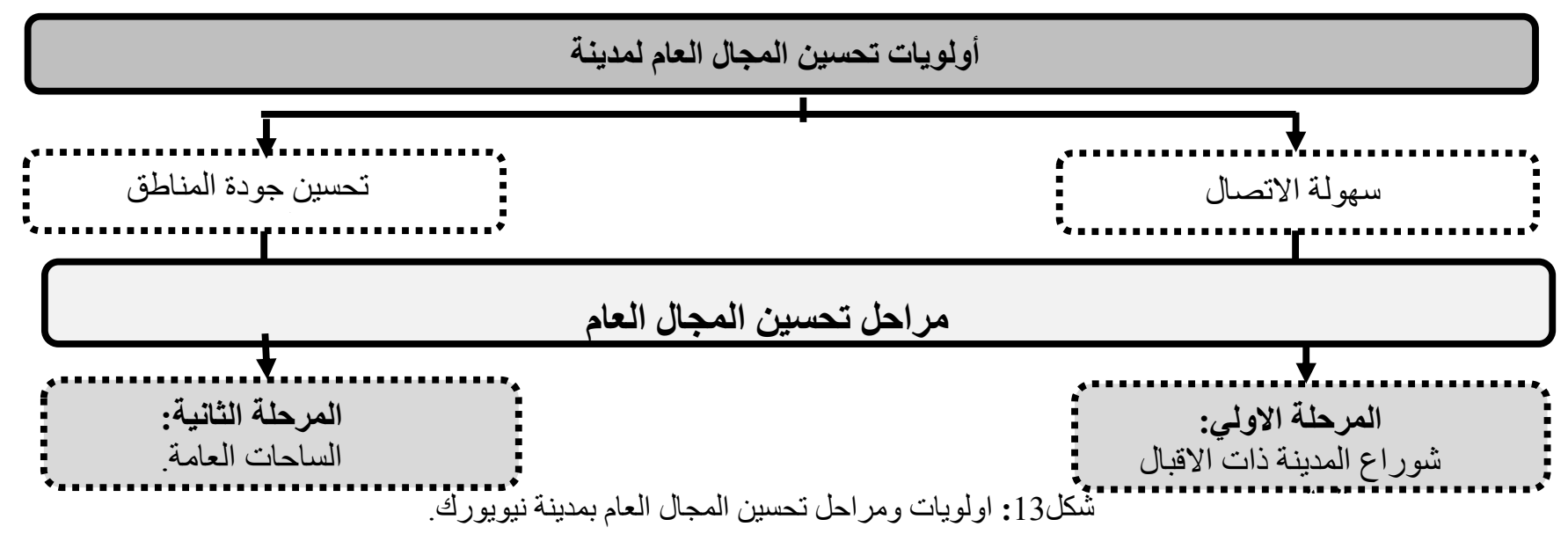

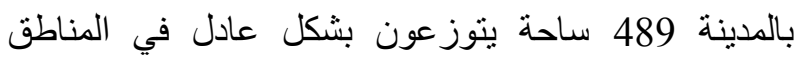

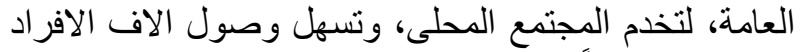

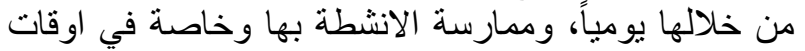
الإجاز ات [17]. شكل15.

2-3-4 سمات المجال العام بمدينة نيويورك:

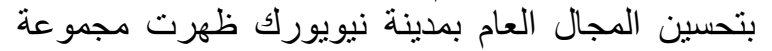
سمات للمجال العام كسهولة الوصول، و التر ابط، و الترحابية، وتتوع الفر اغات العامة، و الابتكار في التصميم [17]. 3-3-4 الجهات الفاعلة: تضافرت جهود الجهات الفاعلة في المدينة، وتتمثل في الحئة

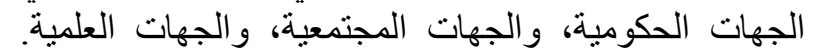

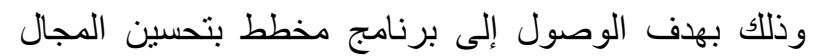
العام لدعم جو انب الحياة المختلفة بالمدينة.

$$
\text { أ- الجهات الحكومية: }
$$

قامت الجهات الحكومية بترتيب الاولويات و القضايا

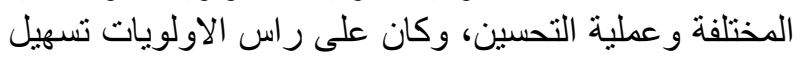

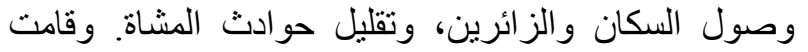

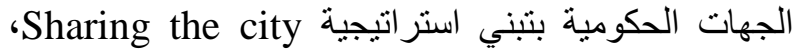

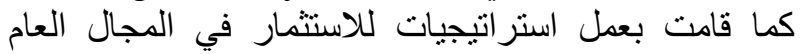

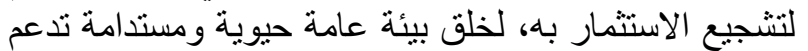
تر ابط المجتمع [19].

أ- الجهات العملية والمجتمعية: قامت الجهات العلمية بعمل العديد من الدية: الدراسات التي

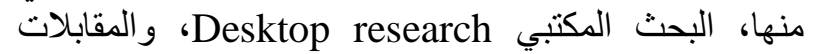

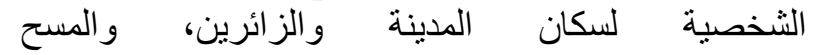

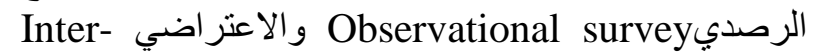
فجاء البحث المكتبي لتحديد الفراغات -rcept survey
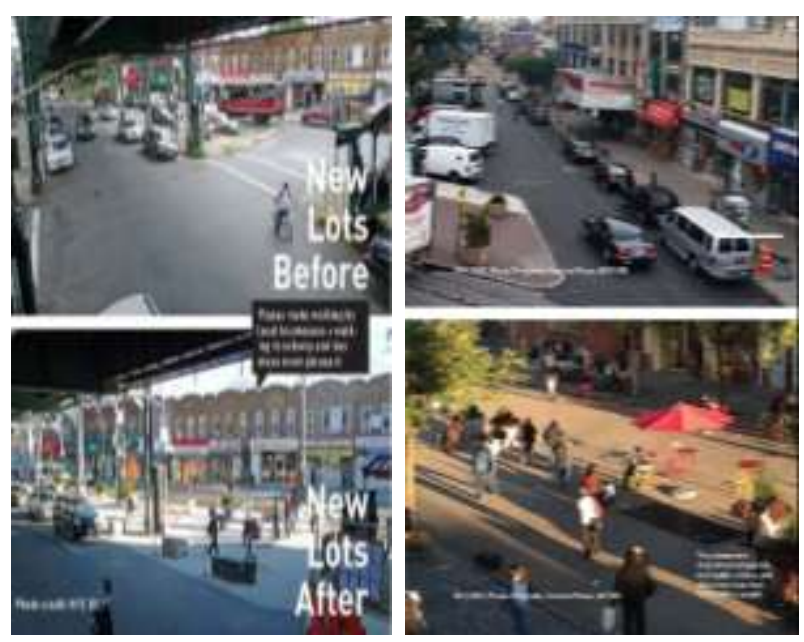

شكل 14 : تحويل أجز اء من شوار مع مدينة نيويورك الى مناطق آمنة اللمشاة و الجلوس قبل ( بالأعلى) وبعد (بالأسفل) [17

ب- المرحلة الثانية الساحات العامة:

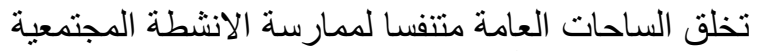

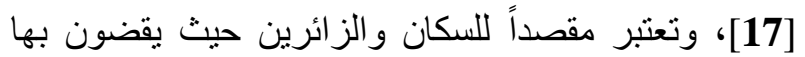
وقتا كبيرا، لخلقها بيئة ممتعة. فكان الهدف من تحندين

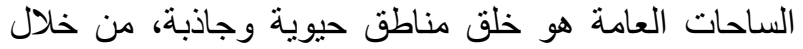
التصميم الجيد لتلك المناطق لهن [18].

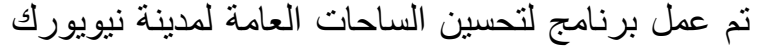

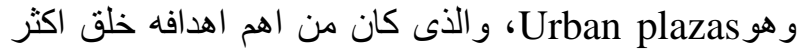

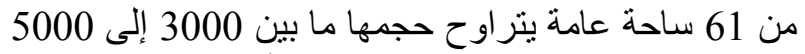

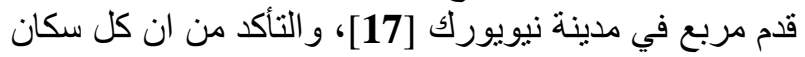

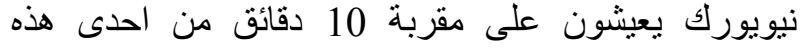
المناطق العامة المفتوحة [16]. وقد بلغ بلغ عدد الساحات العامة 
بالتعاون مع الجهات الفاعلة، التي تقوم بعمل المسح الكمي

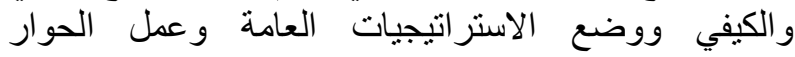

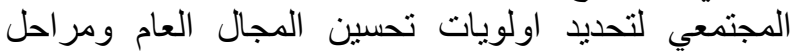
التحسين، والذي يهدف بشكل أساسي الي تحقيق التنمية الاجتماعية و الاقتصادية و الثقافية للمدينة.

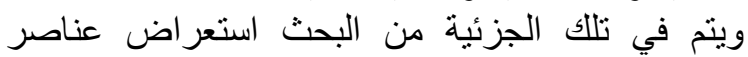

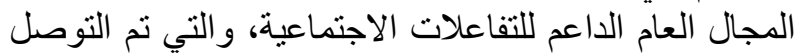

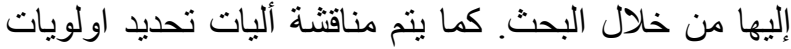

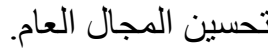

1-5 عناصر المجال العام الداعم للتفاعلات الاجتماعية:

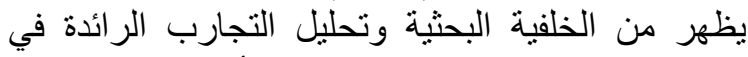
تحسين المجال العام للفر اغات العمرانية، أن التحسين يرتبط التئ

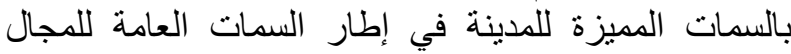

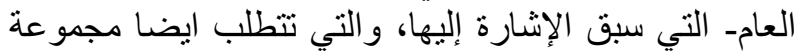

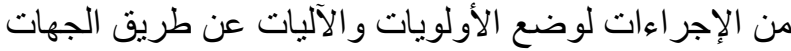

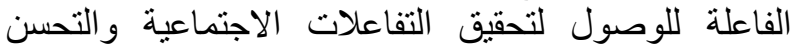

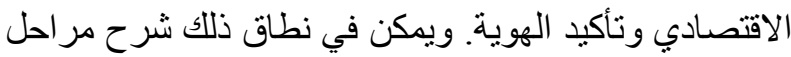
تحديد الأولويات و الاليات، شكل 16، كالتالي:

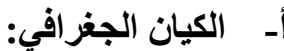

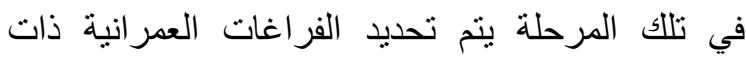
الملكية العامة التي تحتاج إلى تحسين المجال العام داخل

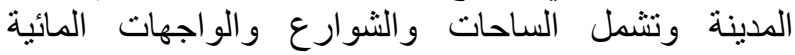

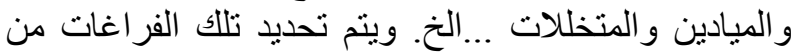
خلال المسح الكمي والكيفي، الذي يقوم به الجهات العلمية

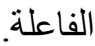

\section{ب- الصفات المكانية:}

و هي المرحلة التي ترنبط بتحقيق مجموعة التهبه الخصائص

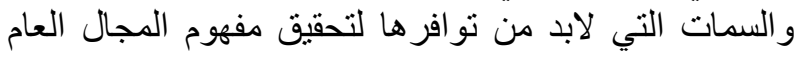

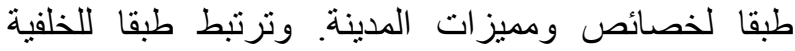

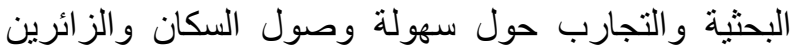

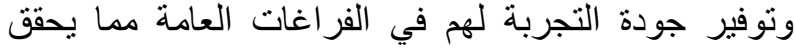

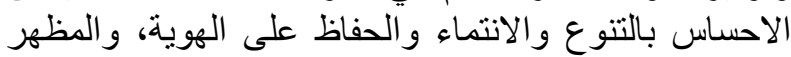
الجيد للمجال العام، والاحساس بالأمن والأل الراحة، والابتكار

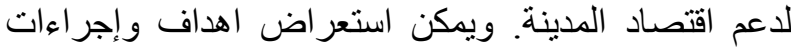
تحقيق أهم هذه السمات، و التي تتداخل فيما بينها، كالتالي:

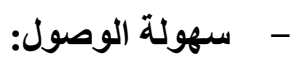

• يهدف لخلق فر اغات ديناميكية نابضة وجاذبة

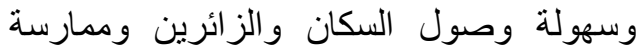

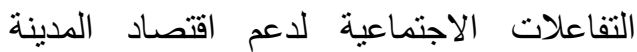

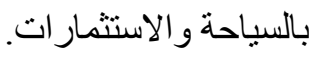
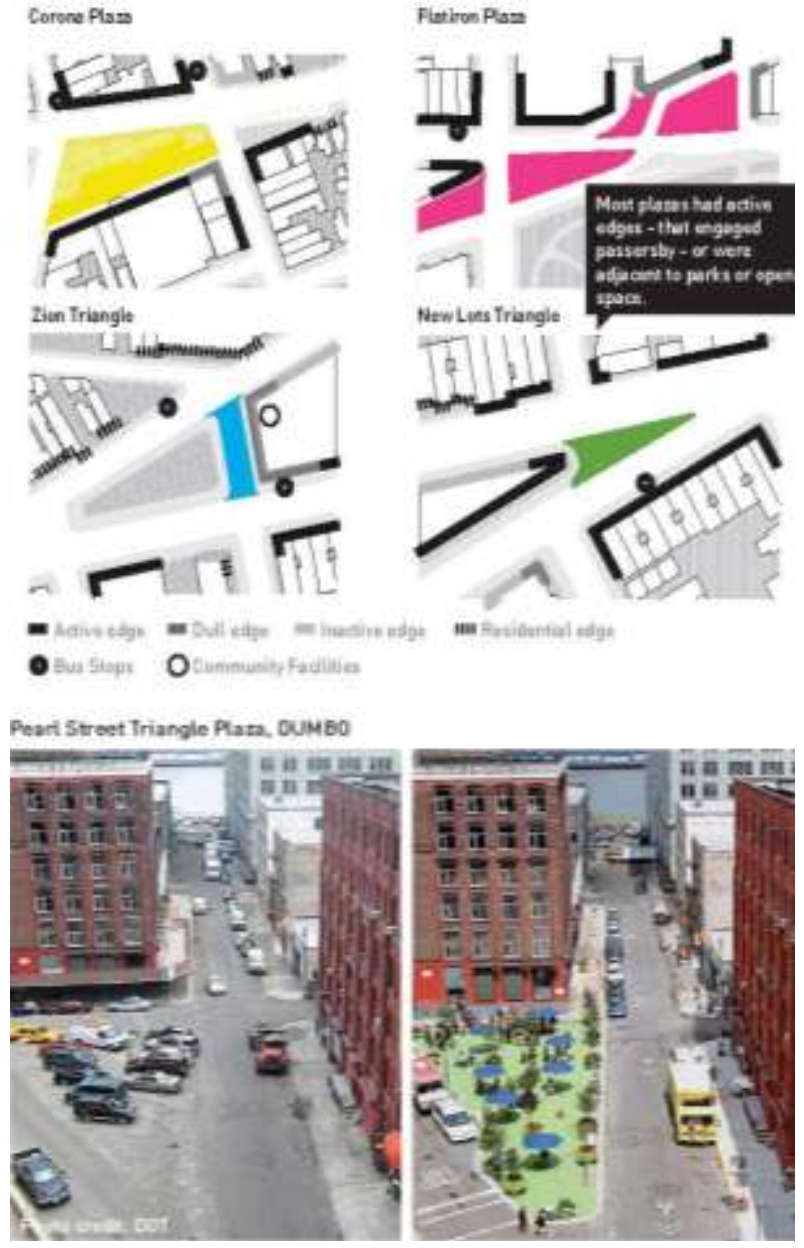

شكل 15 : بعض مخططات خلق الساحات بمدينة نيويورك

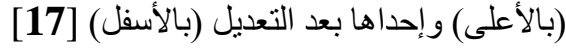

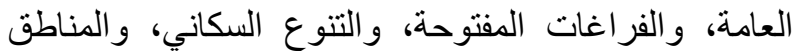
التي يوجد بها معوقات للنقل النشط. اما بالنسبة للمقابلات التهات

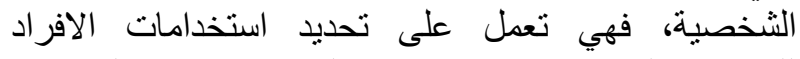

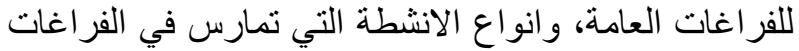

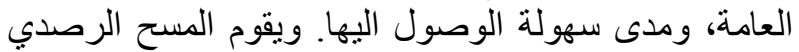

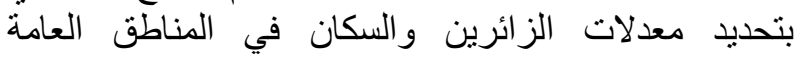

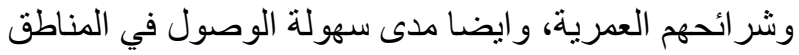

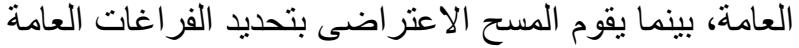
ذات الملكية العامة و الخاصة وسمات الفر اغات العامة [117].

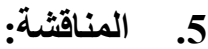

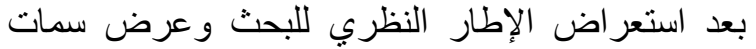

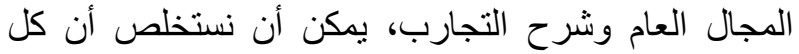

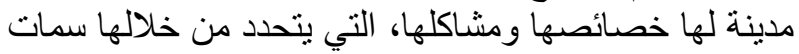

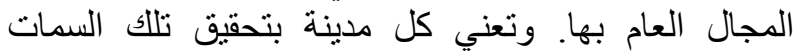


Vol. 42, No. 1. January 2023
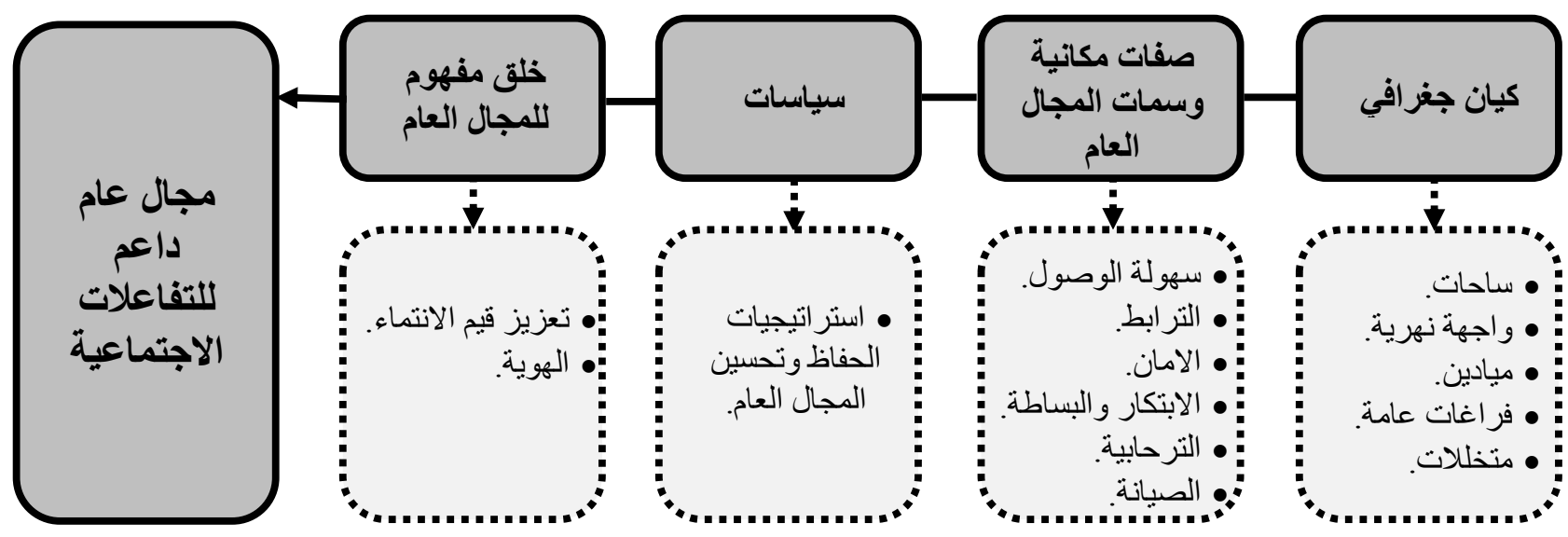

شكل 16: عناصر المجال العام الداعم للتفاعلات الاجتماعية.

الانشطة المجتمعية، وتوفير أماكن جلوس لإعطاء

فرصة للاستمتاع بالمناظر الطبيعية و التزراث.

$$
\text { - - - المظهر الجيد والترابط: }
$$

• يهدف الى تحقيق الانطباع الجيد للزائرين ودعم

اقتصاد المدينة.

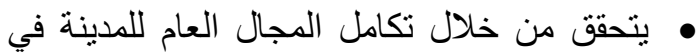

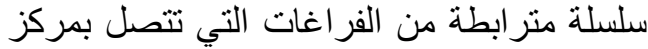

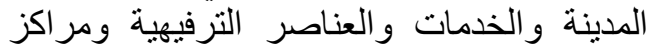

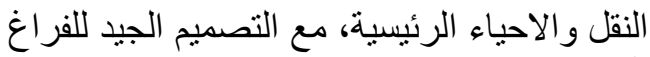

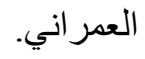

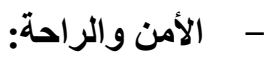

• يهدف لجذب الز ائرين و السكان لممارسة الأنشطة

$$
\text { وتحقيق الانتماء. }
$$

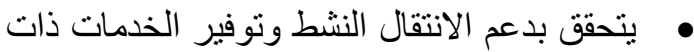

الجودة وخلق ساحات آمنة عن حركة السيار اتل

$$
\text { الكثيفة. }
$$

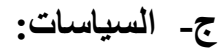

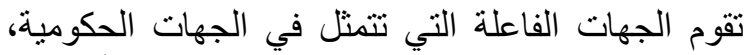

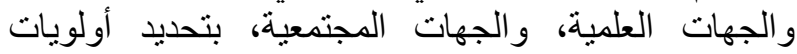
تحسين المجال العام وآليات التنفيذ. ويمكن تحديد دور كل

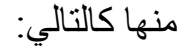

- الجهات الحكومية: تقوم بوضع رؤية المدينة

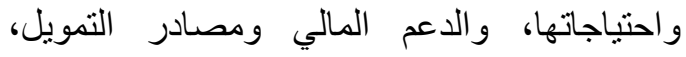
و واستر اتيجية واولويات وانهات عملية تحسين المجال العام. - الجهات العلمية: تقوم بالمسح النوعي، الذي يهدف

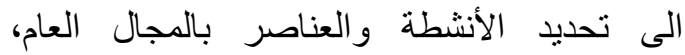

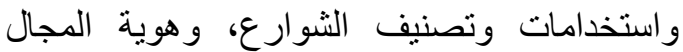

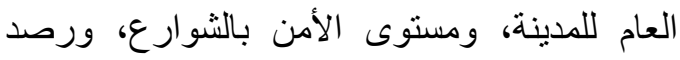

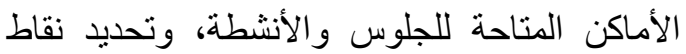

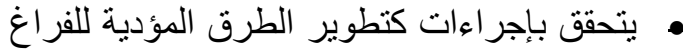

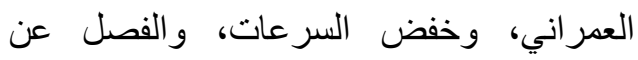

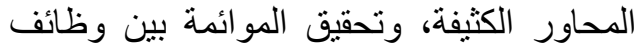
المكان و الحركة في الطرق، وتوجيه ولفئ السياسات

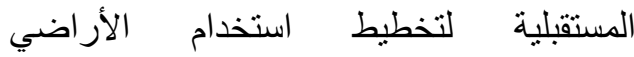
الاستثارية، وتعزيز مرونة شبكة الطرق، وتفعيل النقل النشط Active transport وتقليل

$$
\text { الاعتماد على السيار ات الخاصة. }
$$

\section{- جودة التجربة:}

• يهدف لتقديم اماكن أكثر امناً واخضر ار اً وجاذبية

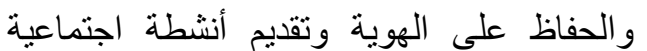
وترفيهية وربط وتكامل فر اغات المدينة.

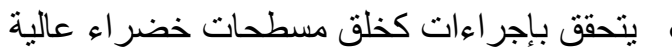

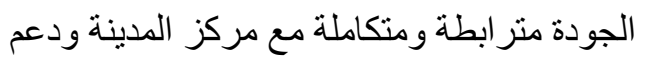

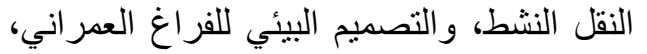

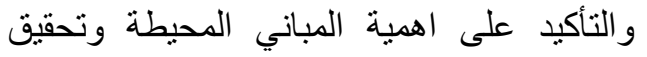
الخصوصية لها وتحسين القدرة على استيعاب الفيان المستخدمين، وتحسين الربط بين الفراغ الداخلي ولئي

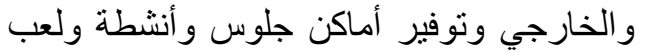

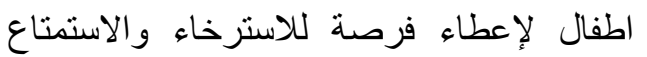
بالبيئة المحيطة.

\section{- - موية المدينة:}

• يهدف للحفاظ على الهوية التاريخية والثقافية للمدينة، بتحسين المجال العام للفر اغات التاريخية

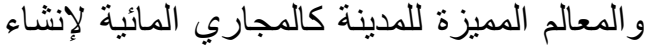

سلسلة متر ابطة من المناطق ذات الجودة العالية.

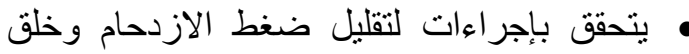
مساحات داخل الفراغات للنقل النشط، وممارسة 
و هي المرحلة الأخيرة للتحسين التي يتعزز عندها قيم

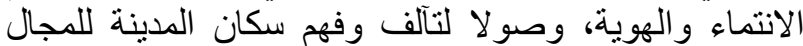

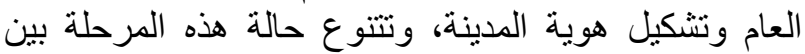

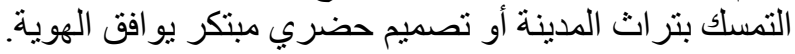
2-5 منهجية تحديد اولويات تحسين المجال العام:

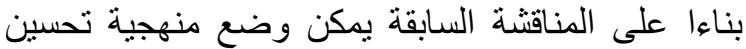

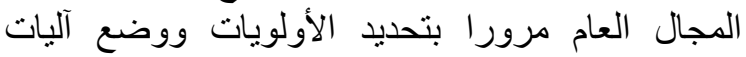
التحسن، كما يظهر بشكل 17، على ثلاث مر احل أساسية:

- المرحلة الأولى، يتم فيها تحديد المشاكل، حيث تقوم

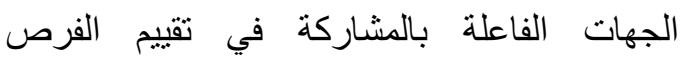

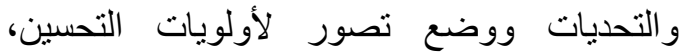
وتحديد مصادر التمويل و الدعم. - المرحلة الثانية، تقوم فيه الجهات المسئولة، بناءاء

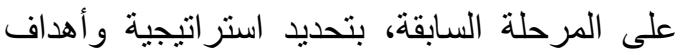
التحسين ووضع أولويات التنفيذ الفعلية بما بحقق لئق
الضعف والتميز للمجال العام، كمعدل ازدحام السيار ات وحالة البيئة وحركة المشاة. وتقوم أيضا بالمسح الكمي الذي يشمل تحديد أعداد

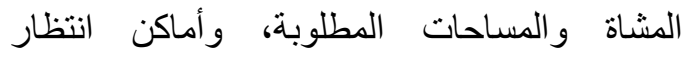
السبار ات ومسار ات الانتقال النشط المتاحة.

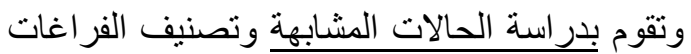

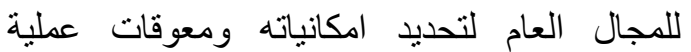

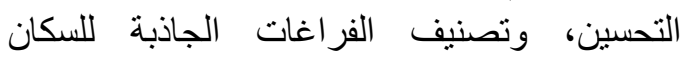
و الزائرين و الفر اغات التاريخية. = الجهات المجتمعية: تقوم بالمساهمة في اختيار

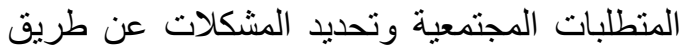

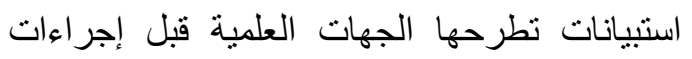

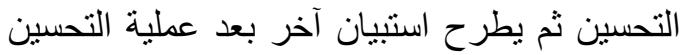
لتقييم الرضا للسكان و الز ائرين. دـ تحقيق مفهوم للمجال العام:

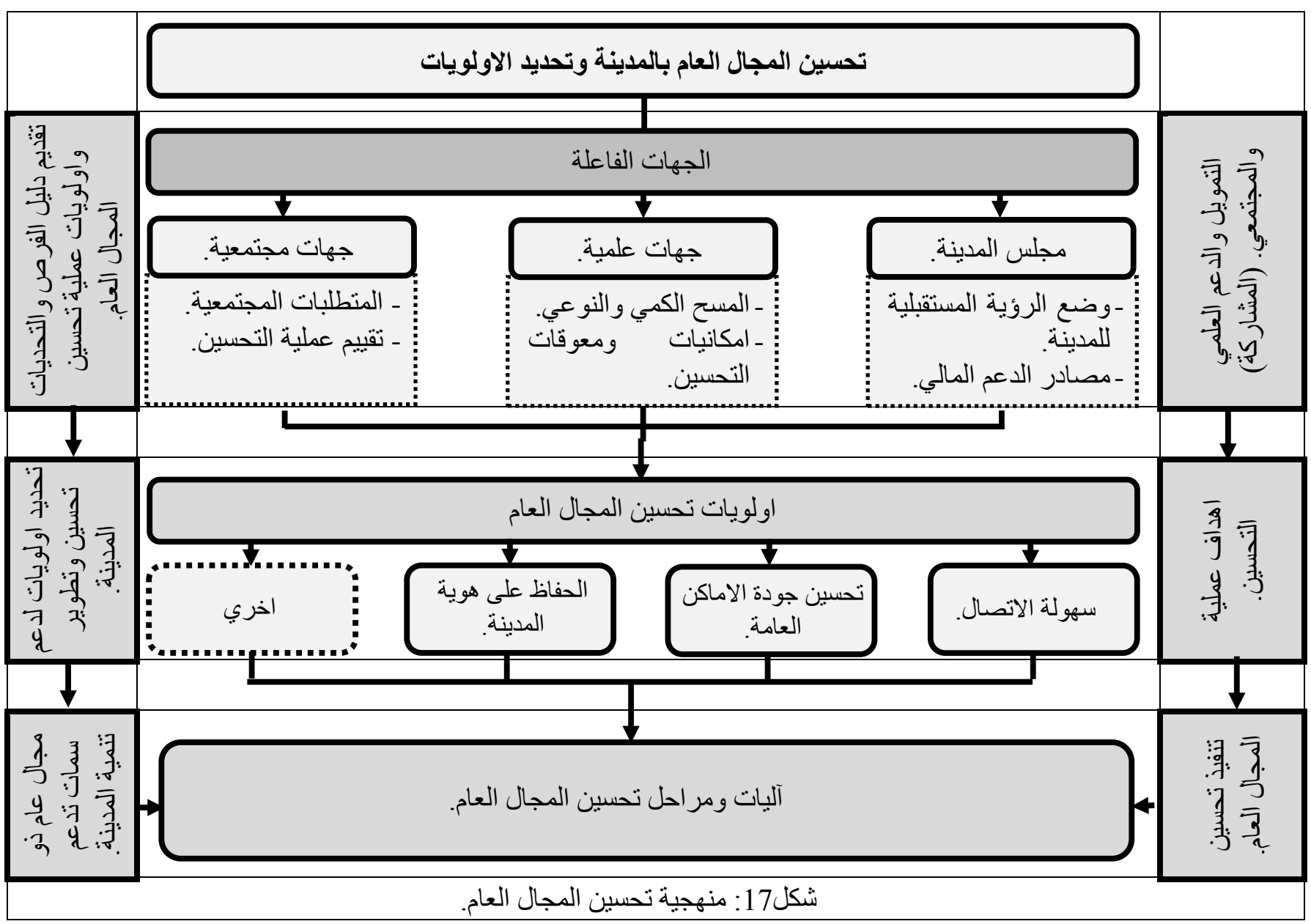




\section{Vol. 42, No. 1. January 2023}

[3] Loretta Ryan, "Healthy Communities and Planning for the Public Realm A Call to Action," Ontario, Canada, 2016.

[4] Manal Ma'rawe, "The role of designing internal public architectural spaces in achieving social communication," Al-Baath University Journal, vol. 41, no. 39, 2017.

[5] Economic \& Social research council, "Briefing public realm," 2014.

[6] Peter Eisenman, Post Urbanism \& ReUrbanism, Roy Strickland, Ed. Michigan: Michigan Debates on Urbanism, University of Michigan, 2005, vol. III.

[7] TfL Urban Design team, Station public realm design guidance. London: Tfl Ueban Design , Grimshaw Architects, BDP, 2015.

[8] Douglas S Kelbaugh, "Three Urbanisms and the Public Realm," 2001.

[9] Greater London Authority , "Exploring London's public realm," London, 2020.

[10] Peter Murray, Fred Manson, and Pam Alexander, Public London: Creating the best public realm. London: Mayor's Design Advisory Group, 2016.

[11] London development agency, Transport for London (TFL), and Mayor of London, Civilizing spaces : improving London's public realm. London: New London Architecture group, 2005.

\author{
أفضل سمات للمجال العام للمدينة.

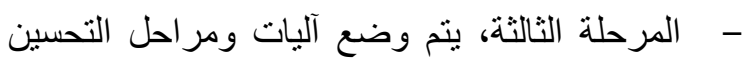

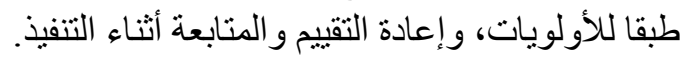

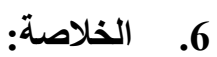

تم في هذه الورقة البحثية استعر اض مفهوم المجال العامٍ

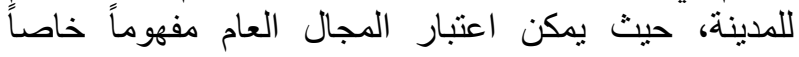

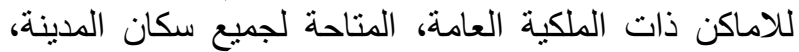
و التي يمارس فيها مختلف الانشطة القادرة على خلى خلق وتطوير الإنه الخصائص الاجتماعية والثقافية والاقتصادية الأنية للمدينة ودعم

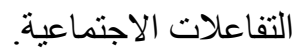
وتعرض البحث للتجارب الر ائدة في تحسين المجال العام

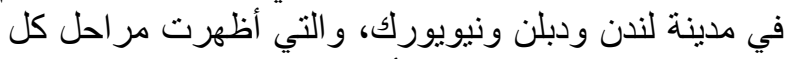
مدينة في تحديد المشكلة والأولويات لتعظئي سمات التئ المدينة

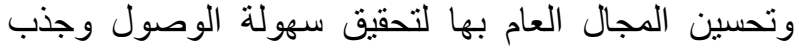

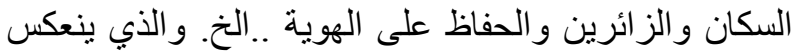

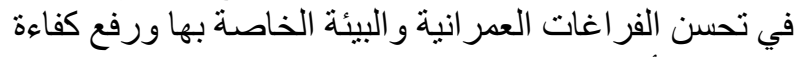

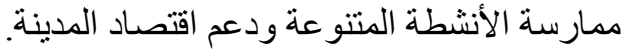

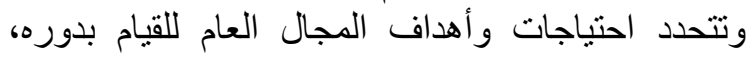

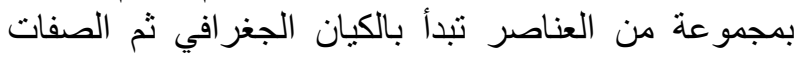

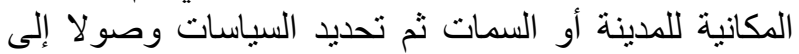
الحصول على المجال العام. وأظهرت المناقشة البحثية الدور الفاعل للجهات العهات المختلفة

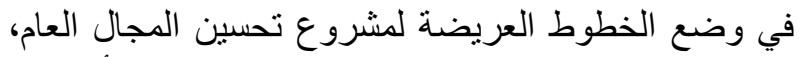

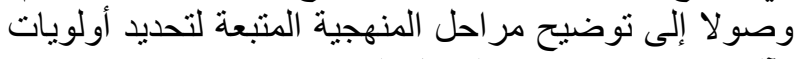
و آليات مشروع لإلتحسين المجال العام.

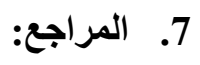

[1] Anirban Adhya, "The public realm as a place of everyday urbanism learning from four college towns," Ph.D. , University of Michigan, 2008.

[2] Khalid Mandeli, "Public space and the challenge of urban transformation in cities of emerging economies: Jeddah case study," Cities, p. (95) 2, 2019. 
Vol. 42, No. 1, January2023

[12] Publica (London based urban design), Public realm vision for victoria.: victoria Business improvement district (BID) LTD.org, 2014.

[13] Dublin City Council, "Your city your space ( Dublin city public realm strategy )," 2012.

[14] Dublin city council, "Dublin city centre (The heart of dublin city centre public realm masterplan)," Dublin, 2016.

[15] Municipal Art Society of New York (MAS) and New Yorkes for Parks group (NY4P), "A Public Champion for the Public Realm," New York, 2020.

[16] Gehl Architects urban quality consultants, "World Class Streets Remaking New York City's Public Realm," London, 2007.

[17] Gehl Studio NY, J. Max Bond Center(JMBC), "Public Life \& Urban Justice in NYC's Plazas," New York, 2015.

[18] Stephan Schmidt, Jeremy Nemeth, and Erik Botsford, The evolution of privately owned public spaces in New York city. New York: Macmillan Publishers, 2011.

[19] Andrea Woodner and Claire Weisz, Sharing The City (Learning from the New York City Public Space Movement 1990-2015).: sharing The City.net, 2017. 